\title{
Net-Zero Energy Districts and the Grid: An Energy-Economic Feasibility Case-Study of the National Western Center in Denver, CO, USA
}

\author{
Benjamin A. Saarloos ${ }^{1}$ and Jason C. Quinn ${ }^{2, *}$ \\ 1 Systems Engineering, Colorado State University, Fort Collins, CO 80524, USA; Ben.Saarloos@colostate.edu \\ 2 Mechanical Engineering, Colorado State University, Fort Collins, CO 80524, USA \\ * Correspondence: Jason.Quinn@colostate.edu; Tel.: +1-970-491-4770
}

check for updates

Citation: Saarloos, B.A.; Quinn, J.C. Net-Zero Energy Districts and the Grid: An Energy-Economic Feasibility Case-Study of the National Western Center in Denver, CO, USA. Buildings 2021, 11, 638. https://doi.org/ 10.3390 /buildings 11120638

Academic Editor: Fabrizio Ascione

Received: 8 November 2021

Accepted: 7 December 2021

Published: 11 December 2021

Publisher's Note: MDPI stays neutral with regard to jurisdictional claims in published maps and institutional affiliations.

Copyright: (c) 2021 by the authors. Licensee MDPI, Basel, Switzerland. This article is an open access article distributed under the terms and conditions of the Creative Commons Attribution (CC BY) license (https:// creativecommons.org/licenses/by/ $4.0 /)$.

\begin{abstract}
Given the enormous impact of buildings on energy consumption, it is important to continue the development of net-zero energy districts. Opportunities exist for energy efficiency and renewable energy on a district level that may not be feasible in individual buildings. Due to the intermittent nature of many renewable energy sources, net-zero energy districts are dependent on the energy grid. The novelty of this work is to quantify and optimize the economic cost and grid independence of a net-zero energy district using the National Western Center (NWC) in Denver, CO, USA as a case study. The NWC is a 100+ ha campus undergoing a major redevelopment process with a planned $170,000 \mathrm{~m}^{2}$ of total building space, an emphasis on sustainability, and a net-zero energy goal. Campus plans, building energy models, and renewable energy performance models of on-site solar, biomass, and thermal renewable energy sources are analyzed in multiple energy scenarios to achieve net-zero energy with and without on-site energy storage. Levelized cost of energy (LCOE) is optimized as a function of variables defining the energy and economic relationship with the grid. Discussion herein addresses trade-offs between net-zero energy scenarios in terms of energy load, LCOE, storage, and grid dependence.
\end{abstract}

Keywords: levelized cost of energy; load/generation balance; net-zero energy campus; net-zero energy district; sustainable energy building design

\section{Introduction}

In the United States, buildings are responsible for $40 \%$ of carbon emissions and consume $75 \%$ of grid electricity [1]. As such, sustainable energy building design has been a growing focus in the last couple decades. Design includes performance goals such as net-zero energy, where efficiency gains are implemented such that the balance of the energy needs can be offset by renewable technologies [2]. More recently, zero energy has been expanded to "communities" [3], noting that larger districts provide opportunities for energy efficiency and renewable energy penetration that may not be feasible in individual buildings [1]. Zero energy district design principles have been outlined as a priority of maximizing: (1) building efficiency, (2) solar potential, (3) renewable thermal energy, and (4) load control [1]. While the goals may be consistent, how zero energy strategies play out in terms of technology and design are unique to each district.

Districts are collections of buildings that can be optimized on their own and in conjunction with each other. The optimization process brings together separate building performance simulation and optimization tools. Optimization is most commonly energy or economic related, but can include building layout \& form, construction, and thermal comfort [4]. The interaction between buildings can impact both their design and performance, such that urban form generation models have been coupled with energy systems programs in energy-driven urban design [5]. Recently, multi-objective optimizations have been applied in case studies with simultaneous goals to minimize greenhouse gas, life-cycle cost, and net exergy deficit [6], or annualized cost and equivalent $\mathrm{CO}_{2}$ emissions [7]. 
Given the intermittent nature of many renewable energy resources, it is important to consider the dynamic load/generation energy mismatch of the district and balancing competing needs of self-sufficiency, investment cost, and reliability [8]. The mismatch between load and generation at the building level can be better managed when an aggregation of buildings is considered [9], including implementing specific strategies to improve load matching [10]. Energy storage is another technology to help manage this balance, and has been shown to offer a net-zero cost advantage over an equivalent system void of storage [7]. Some studies have concluded that traditional thermal storage is the only economically viable energy storage [11], but other economic analyses demonstrate the viability of lithium ion battery storage [12,13].

Campuses are districts of interest because of the inherent relationship between buildings and available space. Previous efficiency-focused campus case studies have noted the difficulty of achieving net-zero in densely developed neighborhoods [14-16]. The National Western Center (NWC) in Denver, CO, USA in is a $100+$ ha $(250$ ac) campus centrally located at the intersection of the South Platte River and Interstate-70, and is one of six Zero Energy Districts Accelerator (ZEDA) participating partners previously identified as prime candidates to study the evolution of net-zero energy concepts from individual buildings to districts $[1,17]$. Attia et al. identify a large number of varying building simulation and optimization tools [4], while Allegrini et al. state that a significant challenge in relation to district energy system modeling is to provide simple tools that can support decision makers early in the design process at both the building and urban levels [18].

The novelty of this work is to advance the development of net-zero energy districts by investigating the economic impact of a key underlying net-zero energy assumption: the energy grid. Net-zero renewable energy deployment is investigated in terms of economic viability and grid energy dependence using the NWC as a case study. EnergyPlus [19], a popular building simulation tool [4], is used as part of an energy demand/production model with parameter optimization to understand the economic feasibility of district level net-zero energy. Levelized cost of energy (LCOE) is optimized as a function of variables defining the energy and economic relationship with the energy grid and quantified for micro-grid scenarios that achieve grid independence. The results quantify the required involvement of the energy grid for general economic feasibility, and demonstrate the impact of stored energy on reducing both LCOE and grid energy dependence.

The NWC is in the midst of a major redevelopment process, with a planned $170,000 \mathrm{~m}^{2}$ (1.8 million $\mathrm{ft}^{2}$ ) of total building space and an emphasis on sustainability, as evidenced by defined goals to minimize annualized energy demand, maximize installed renewable energy-generation potential, and couple site and building operations to maximize energy efficiency performance with low maintenance [20]. The NWC master plan specifically outlines the goal of a net-zero energy district, prioritizing technical and behavioral strategies to increase efficiency and using on-site renewable energy sources [21]. The NWC features key renewable energy opportunities including large rooftops available for solar PV, the potential for district-scale heat recovery from $2 \mathrm{~m}$ (72 in) diameter sewer pipe running above ground on site [21], and a potential biomass fuel source from the annual Western Stock Show.

This study is a net-zero site energy consumption analysis [3], meaning measured energy consumed and generated is limited to the geographical location of NWC. Net-zero energy district design principles are applied to the NWC campus, with an emphasis on the principles of maximizing solar potential and renewable thermal energy. The presence of a grid is assumed for electrical energy import and export [22], and the hourly load/generation energy balance is investigated in conjunction with on-site battery energy storage. Readily available tools and models are leveraged, including NREL's PVWatts [23] to estimate photovoltaic electricity potential, and EnergyPlus [19] with International Energy Conservation Code (IECC) 2015 building models [24] to forecast campus energy loads. In contrast to other studies, the economic analysis is limited to direct business costs, void of tax incentives on capital [25] and feed-in-tariffs on exported PV energy [7,26]. 


\section{Materials and Methods}

The energy analysis consists of three steps: (1) estimating energy load, (2) assessing available renewable energy and quantifying its generation capacity, and (3) performing a net-zero energy and economic analysis of the energy scenarios.

\subsection{Energy Load}

The NWC master plan outlines a mix of existing and new buildings in the final campus configuration [21]. Existing buildings that will remain include the Denver Coliseum, Hall of Education, Events Center, and a renovated Maintenance building. New buildings include the Colorado State University Water Resources Center (CSU WRC), Animal Health building, Stock Show complex, Livestock Hall and Arena, and the Equestrian Arenas and Paddocks.

Defining the energy load of the campus begins with examining collected utility data for the facilities that will remain in place. Three years of utility data (2014-2016) are analyzed and averaged for each of the defined building complexes. Electricity consumption is billed in $\mathrm{kWh}$ and natural gas consumption in therms. For clarity of reporting, total energy load is converted and summed in units of Mega-Joules (MJ) but distinguished between electricity and natural gas energy load types.

For future buildings, detailed models developed for the International Energy Conservation Code (IECC) [24,27] are used to estimate load on a per-square-meter of building basis. In terms of climate, Denver is located in Zone 5B, described as "Cold, Dry". The representative city of this climate is Boise, Idaho [28]. Of the various defined IECC commercial building types, "secondary school" was selected for the CSU WRC building, "outpatient healthcare" for the Animal Health Building, and "warehouse" for the Stock Show, Livestock, and Equestrian building complexes.

The IECC building models are run in the EnergyPlus [19] program with Denver TMY3 (Typical Meteorological Year) data to generate an hourly energy usage profile. Areaweighted IECC secondary school and outpatient healthcare are applied directly to the CSU WRC and Animal Health Buildings. A slight modification is made to the IECC warehouse type building to better correlate with the current NWC energy usage profile (see Figure A1). While maintaining the annual EUI, the hourly weighting is shifted to heavier use in January and February based on NWC historical energy usage data. This usage profile is reflective of the timing of the annual National Western Stock Show.

One of the goals of the NWC rejuvenation project is to increase show and event activities throughout the year. To that end, a projected campus load scenario called " $2 \times$ Summer" is modeled where daytime energy usage from 15 May to 15 August is multiplied by a factor of two. This modification is intended to capture the energy impact of additional summer event activities at the site.

\subsection{Renewable Energy Generation}

Following the guidelines of the Net-Zero Energy Building (NZEB) classification system [2], design priority is given to local in-building and on-site options over off-site and purchased Renewable Energy Credits (RECs). To that end, the focus of this study is limited to on-site renewable energy resources. A preliminary high-level renewable energy feasibility assessment of the NWC campus concluded that solar PV, heat pump, and biomass are applicable on-site renewable energy sources (see Table A1).

\subsubsection{PhotoVoltaic Electricity}

Colorado is a state with good solar resources, and Denver $\left(1800 \mathrm{kWh} / \mathrm{m}^{2}\right.$ annual horizontal solar irradiation [23]) is on the edge of the southwestern region of the country where photovoltaic electricity is considered the most affordable [25]. The PV performance analysis begins with examining each building within the layout of the NWC campus [21]. Available roof areas are determined for both existing and future buildings, including whether the roof is flat or pitched. For flat roots, PV panels are positioned facing south 
and tilted up $40^{\circ}$ from the horizontal [29] position to maximize the total annual electricity energy generation. For pitched roofs, PV panels are mounted at a standard $7^{\circ}$ tilt roof pitch, and oriented per roof segment with the azimuth directional angle measured from north [30].

Assuming a nominal PV panel power density of $175 \mathrm{~W} / \mathrm{m}^{2}$ [31], the capacity of the panel array is determined for each roof segment based on an area analysis and fed with tilt and azimuth geometry into the NREL PVWatts calculator [23]. The output of hourly $\mathrm{kWh}$ of electricity is calculated for each building and summed annually over the entire campus. The economic analysis assumes a $0.75 \%$ annual degradation in PV output for each installation. Capital and operating costs of $1850 \$ / \mathrm{kW}$ and $15 \$ / \mathrm{kW}$-yr. for PV panels were obtained from NREL commercial system cost estimates [25,32].

\subsubsection{Combined Heat and Power}

A unique feature of the NWC campus is the available biomass of animal bedding waste from the National Western Stock Show. A rough estimate of $1000 \mathrm{t}$ of available bedding is calculated based on stock yard pen areas [33] and the density of wheat straw [34]. Since the Stock Show is in January, the availability of the biomass coincides with the greatest need for thermal energy.

The renewable energy potential of the biomass is calculated based on the performance of Biomax Combined Heat and Power (CHP) systems [35]. The Biomax systems are built from a nominal gasification module which can generate $155 \mathrm{~kW}$ of net electricity plus an equal amount of heating energy. The baseline system is a coupled $155 \mathrm{~kW}$ syngas engine, while a larger system comprised of a more efficient $710 \mathrm{~kW}$ engine is coupled with four gasification modules which allows output to be throttled in increments of $25 \%$. Capital investment costs of 6000 to $8000 \$ / \mathrm{kW}$ for installation of the CHP systems were estimated from conversation with Biomax [36], and $100 \$ / \mathrm{kW}$-yr. operating costs are estimated from the NREL renewable energy costs overview [32].

\subsubsection{Heat Pump}

Heat pump technology is included as a renewable energy-generation resource, even though it does not generate energy to offset load as the PV and CHP technologies do. Instead, it reduces the campus gas and total energy loads. A heat pump requires a thermal sink from which to exchange heat. Most commonly, the source is the ground, leading to the term Ground-Source Heat Pump (GSHP). Given the size of the campus, the NWC has more than adequate ground space to meet heat pump needs. However, the NWC site also features large $2 \mathrm{~m}$ (72 in) diameter above-ground sewer pipes to support wastewater heat exchange as a thermal energy source for the campus.

This work considers both opportunities by assuming that the heat pump energy performance is similar for GSHP or wastewater energy exchange. To quantify the energy load reduction, individual building heating and cooling energy loads are backcalculated using the $80 \%$ natural gas heating efficiency and 3.4 Coefficient of Performance (COP) cooling metrics of the IECC building models [27]. The heat pump performance is modeled with a COP of 2.9 and 4.5 in heating and cooling modes, respectively, reflecting a recent GSHP study conducted for Colorado State University's Moby Arena (see Tables A5 and A6). The same study yielded heat pump renewable energy capital, and operating costs of $600 \$ / \mathrm{kW}$ and $1 \$ / \mathrm{kW}$-yr. are calculated as increases over a conventional heating and cooling approach. The main cost difference is the in-ground heat exchanger (i.e., "bore-field"). An estimate of the cost of wastewater heat exchangers [37] yielded numbers similar to the bore-field cost (in $\$ / \mathrm{kW}$ ), such that the general heat pump costs of this study are applicable for both thermal sources. Due to the differences in operating temperatures and the building infrastructure to support them, a given energy scenario may leverage CHP or HP technologies, but not both. 


\subsubsection{Energy Storage}

Given the available wastewater and ground thermal resources, energy storage in this analysis is limited to lithium ion battery electrical energy storage. The capital cost of battery storage is assumed to be $250 \$ / \mathrm{kWh}$, reported as a mid-range cost estimate in 2018 dollars for projected 2025 costs [38]. This future cost was selected since the electrical storage is implemented beginning in Phase 4 of the campus development, six years into the future (see Figure A3). Battery energy level and charging/discharging is analyzed on an hour-by-hour basis in the load/generation energy balance method. The difference with storage is that energy import/export priority is given to the battery first, and second to the grid. A $90 \%$ round trip energy efficiency was assumed for the storage analysis based on the performance of commercially available batteries [39] coupled with a low energy-averaged discharge:capacity rate (i.e., battery "C rate") [40] and recognizing that inverter losses are included in the PV generation model [41].

\subsection{Load/Generation Balance}

The campus energy profile is analyzed on an hour-by-hour basis using modeled load and generation data for each phase of the NWC development. Mismatch between load and generation is analyzed separately for each energy carrier (electricity and natural gas) [42]. If the campus electricity power demand exceeds the renewable electric generation for a given hour, then there is a net electrical load, and energy must be imported from the grid. Conversely, if campus renewable electric generation exceeds the electrical power demand, then there is a net generation, and excess electricity is exported to the grid. For natural gas, when heating energy demand exceeds the renewable heat energy generation, natural gas energy is imported from the grid. There is no export of heat energy in this analysis since CHP operation is governed by heat energy demand. A technical-logical schematic of the movements of energy resources, electricity, and heat is shown in Figure 1. The general technologies considered are presented with electric and thermal distribution systems needed to exchange energy between buildings.

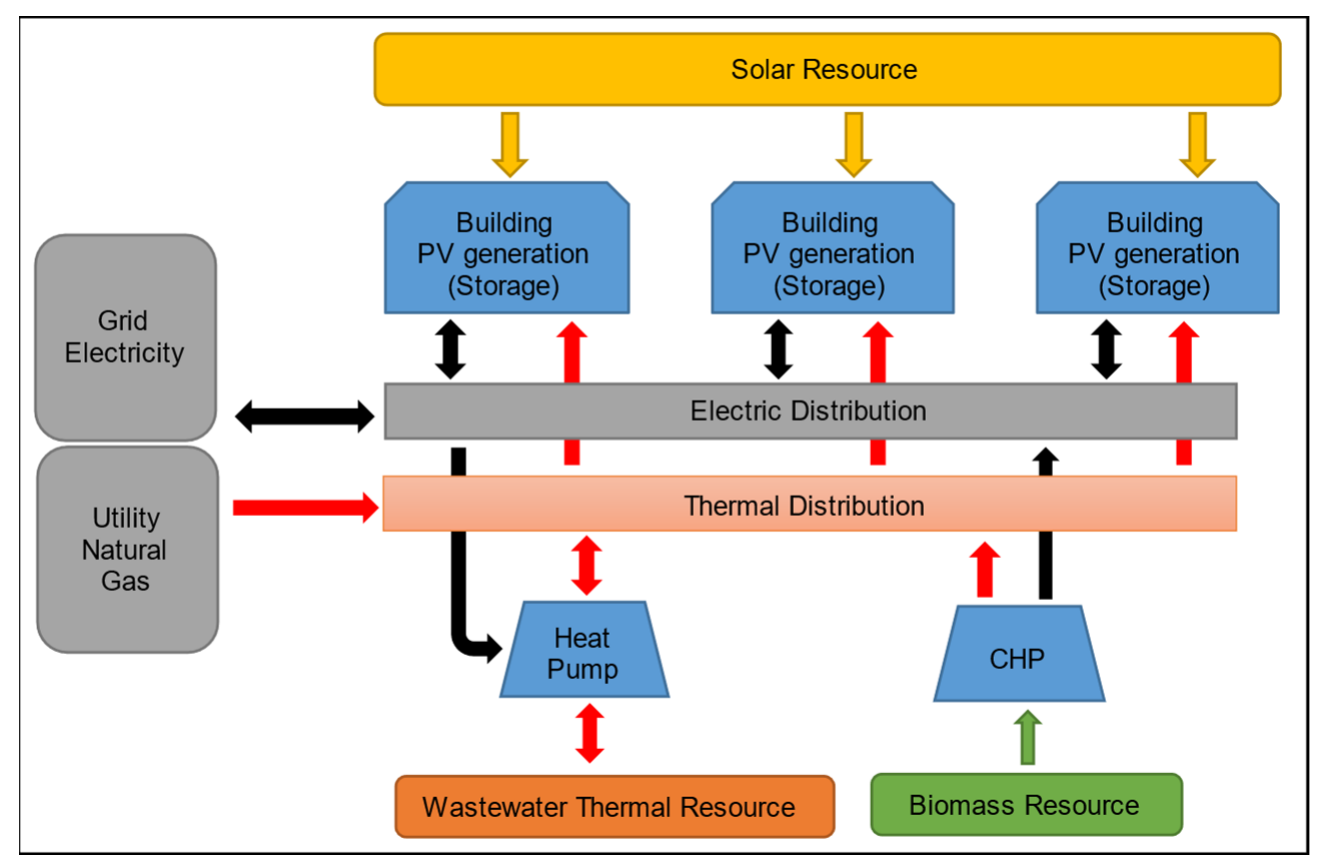

Figure 1. Technical-logical schematic for the load/generation analysis. Arrows indicate direction of (or bi-directional) flow of energy resources as well as electricity (black) and heat (red). The analysis assumes the presence of electric and thermal distribution systems to distribute electricity to and from buildings, as well as distribute heat to and from the wastewater thermal resource via the heat pump. Electricity flow with the grid is bi-directional (can be exported), but useful heat energy cannot be exported from the campus. 


\subsection{Energy \& Economic Analysis}

Energy and economic analyses are conducted over a 30-year period, in line with NREL's Annual Technology Baseline's (ATB) capital recovery period and PV technology lifetime [43]. The first nine years contain five phases of new buildings (Stock Yards, CSU WRC, Animal Health, Livestock, Equestrian), such that year 10 is the first "steady state" year in terms of energy load and generation (see Figure A3). The hourly summed annual energy balance is analyzed for each phase and rolled into the analysis. For this mismatch between load and generation, the analysis assumes an electricity buy:sell ratio of 3 to 1 for energy exported to the grid. Economically, this means that three $\mathrm{kWh}$ of electricity must be sold back to the grid to offset the cost of one kWh purchased (imported).

Capital and operational costs are combined with the modeled energy balance of the system and characterized temporally to calculate LCOE on based on a 30-year discounted cash flow rate of return. Key economic parameter assumptions include loan assumptions, internal rate of return (IRR), depreciation, and taxation [44]. The loan terms are assumed to be $40 \%$ equity of the total capital with $8 \%$ interest over a 10 -year term. Loan interest payments are counted as an operating expense. Depreciation is modeled with a 7-year Modified Accelerated Cost Recovery System (MACRS) and impacts the taxes paid with a $35 \%$ assumed tax rate. An IRR of 5\% is assumed, based on ATB's nominal weighted average cost of capital rate for commercial PV in recent years [45,46].

\subsection{Model Sensitivity}

A sensitivity analysis of the LCOE model is conducted for the scenarios achieving net-zero energy status. The analysis is conducted by calculating the resultant change in LCOE for a $10 \%$ positive and negative change in each of the eleven model parameters. A least squares linear model fit is run to compare the effects of the various model parameters based on a calculated $t$-ratio for each model parameter. A critical $t$-ratio is defined based on ten degrees of freedom for eleven parameters, and a $95 \%$ confidence interval. The effect of a model parameter is considered "significant" if it exceeds this defined critical $t$-value.

\section{Results}

Energy analysis results include spatial and temporal characteristics of the load and generation of the campus. A load/generation balance is conducted on six defined scenarios to determine which ones meet the net-zero energy target on an annual basis. The LCOE is calculated with the corresponding technology solutions compared for scenarios successfully achieving net-zero energy. Sensitivity analysis is used to identify model parameters that have a significant impact on the LCOE. Energy analysis is conducted with and without energy storage, with the results showing while net-zero energy is achievable. The economic feasibility is dependent on the buy:sell price relationship with the electric grid.

\subsection{Campus Energy Load}

Campus energy load is calculated as a total energy sum of electric and natural gas. The Normal and $2 \times$ Summer load profiles are coupled with and without Heat Pump (HP) technology to create four unique load scenarios deemed Normal, Normal HP, $2 \times$ Summer, and $2 \times$ Summer HP. Figure 2 graphically displays the four scenarios with color-differentiated electric and natural gas consumption.

Implementing heat pump technology has two significant impacts on the load. First, the relative portion of energy load is shifted more heavily toward electric over natural gas. Campus-wide, the HP electric:natural gas ratio shifts from $77: 23 \%$ to $89: 11 \%$ for the Normal load profile (see Table A2). The second significant load impact is a 10\% reduction in total energy load, most visible in January and February. Heat pumps actually increase electric load, but since the heating COP is greater than one, the total energy load of the campus is reduced (i.e., "site"). It is recognized that electricity is a more refined energy source than natural gas and must be created from another fuel (i.e., "source"). However, even when 
a site/source conversion of 3.5 [47] is applied, the heat pump maintains a source energy reduction in addition to the more obvious site energy benefit.

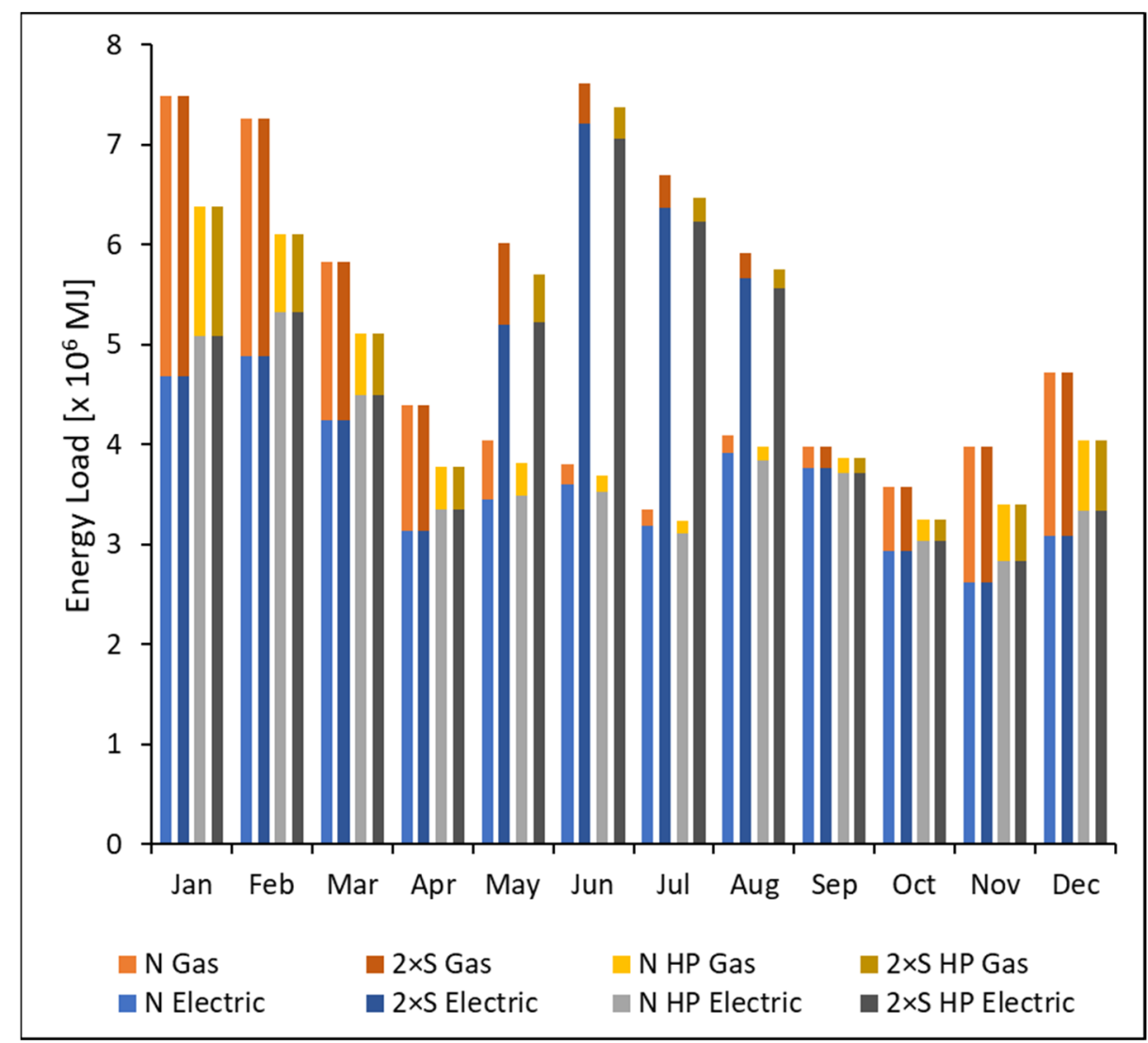

Figure 2. NWC Normal $(\mathrm{N})$ and $2 \times$ Summer $(2 \times \mathrm{S})$ monthly energy load profiles. The $2 \times \mathrm{S}$ profile doubles the daytime load from 15 May to 15 August, resulting in a 19\% annual load increase. The $2 \times$ S June load also exceeds the normal peak load in January. Implementing Heat Pump (HP) technology lowers the annual load by $10 \%$ in both Normal and $2 \times \mathrm{S}$ load scenarios, with the most significant impact in January and February.

The $2 \times$ Summer profile creates a heavy summer electric load, such that the June energy load exceeds the normal January peak. The NWC campus is home to the stock show in January and thus has a dramatic load in the winter during this event. The $2 \times$ summer load is intended to represent increased load of the campus due to new events scheduled. The $2 \times$ Summer load profile has the highest total energy load, 19\% higher than Normal. The minimum annual load profile is the Normal HP, which is $90 \%$ of Normal. These shifts in campus energy loads will significantly impact the load/generation balance and the technological solutions that can meet net zero energy.

The NWC load is analyzed in terms of its building-to-building distribution based on both area and energy (see Figure A2). The CSU WRC and Animal Health buildings represent only $12 \%$ of the campus building area but comprise over $27 \%$ of the total energy load. Conversely, the livestock and equestrian building complexes represent $45 \%$ of the building area, but only $25 \%$ of the energy load. Since the PV generation potential is proportional to building area, the livestock and equestrian complexes are expected to generate a surplus of energy relative to their individual building loads that could offset deficits from other buildings. This is a benefit of conducting a campus-wide analysis and implementation of a district solution in terms of energy.

The difference in distribution between building area and energy is reflective of the range of energy use intensity (EUI) for the buildings across campus (see Table A3 for details). The existing Events Center, Hall of Education, and Coliseum range from 286 
to 508 (25 to 45$) \mathrm{MJ} / \mathrm{m}^{2}$-yr. (kBTU/ft' ${ }^{2}$-yr.). The Stock Show, Livestock, and Equestrian complexes are the lowest at $183(16) \mathrm{MJ} / \mathrm{m}^{2}$-yr. $\left(\mathrm{kBTU} / \mathrm{ft}^{2}\right.$-yr.) compared to a campus high of 1180 (104) MJ $/ \mathrm{m}^{2}$-yr. (kBTU/ $/ \mathrm{ft}^{2}$-yr.) for the Animal Health building. It is noted that the assumed EUI of 183 (16) MJ $/ \mathrm{m}^{2}$-yr. (kBTU/ $\mathrm{ft}^{2}$-yr.) is lower than all existing NWC building structures. However, this reduction is in agreement with historical IECC models from pre-1980 to $2015[48,49]$ that reflect a greater than 50\% EUI reduction largely attributed to more energy-efficient building design practices. The campus-wide EUI ranges from 297 (26) MJ $/ \mathrm{m}^{2}$-yr. (kBTU/ $\mathrm{ft}^{2}$-yr.) in the Normal HP load scenario to 395 (35) MJ $/ \mathrm{m}^{2}$-yr. $\left(\mathrm{kBTU} / \mathrm{ft}^{2}-\mathrm{yr}\right.$.) for $2 \times$ Summer.

\subsection{Campus Energy Generation}

Since the scope of this work is limited to on-site technologies, energy generation on campus is from PV and CHP sources. The PV-generation capacity of a building is proportional to building footprint, and as expected, the high EUI WRC and Animal Health buildings are unable to generate enough electricity to offset their direct needs (see Table A4). However, the low EUI Stock Show, Livestock, and Equestrian complexes each generate two to three times the electricity that they need individually, and can thus make up this shortfall in the district analysis.

With PV as the baseline for campus energy generation, CHP energy generation is added to total generation capacity to achieve a net-zero energy campus. Figure 3 presents month-to-month total energy generation (electric plus heat) for three energy-generating scenarios: PV only, PV plus Base CHP, and PV plus Large CHP. Base CHP on/off operation is governed by the hourly demand for heat. The large CHP system is throttled in increments of $25 \%$ in proportion to the $2 \times$ Summer profile heat demand. The resulting base and large CHP duty factors are $72 \%$ and $55 \%$ of annual capacity, respectively. The NWC biomass assessment estimates there is enough fuel to power the base CHP system for the full year, but additional biomass must be supplied to support the larger $\mathrm{CHP}$ system generation. To qualify as an on-site renewable energy source, the waste stream must be generated and processed within the district [3]. The assumption is made that the source of this fuel would be the campus solid waste stream, including briquetted food scraps, cardboard, and plastics [35].

Even though heat pump technology reduces energy load rather than actually generating energy, its energy impact on the NWC campus can still be compared to that of PV and CHP generation as shown in Table 1. The table data for PV and CHP is the annual sum of the monthly energy-generation profiles of Figure 3. The reported HP energy generation is the resulting decrease in energy load, where a negative value (in parenthesis) indicates a load increase. The table shows that PV is the dominant source of energy generation. The HP energy impact is comparable to the generation capacity of the base CHP, while the large $\mathrm{CHP}$ generates more than three times the energy of the base CHP scenario.

Table 1. NWC annual energy-generation capacity. Capacities are listed by renewable energy type and technology. Heat Pump (HP) is reported as a parenthesized negative electric generation, meaning that electric load increases, and a positive heat generation, meaning natural gas load is reduced. Thus, the total energy generation reported in the table is the energy load reduction compared to a non-HP scenario.

\begin{tabular}{|c|c|c|c|c|c|}
\hline & \multirow{2}{*}{ PV } & \multicolumn{2}{|c|}{ HP } & \multicolumn{2}{|c|}{ CHP } \\
\hline & & Normal & $2 \times$ Summer & Base & Large \\
\hline Capacity $[\mathrm{kW}]$ & 10,200 & \multicolumn{2}{|c|}{3600} & 155 & 710 \\
\hline Electric Generation $\left[\times 10^{6} \mathrm{MJ}\right]$ & 53 & $(1.6)$ & $(1.5)$ & 2.8 & 9.9 \\
\hline Heat Generation $\left[\times 10^{6} \mathrm{MJ}\right]$ & - & 7.5 & 7.7 & 2.7 & 7.9 \\
\hline Total Energy Generation $\left[\times 10^{6} \mathrm{MJ}\right]$ & 53 & 5.9 & 6.2 & 5.5 & 18 \\
\hline
\end{tabular}




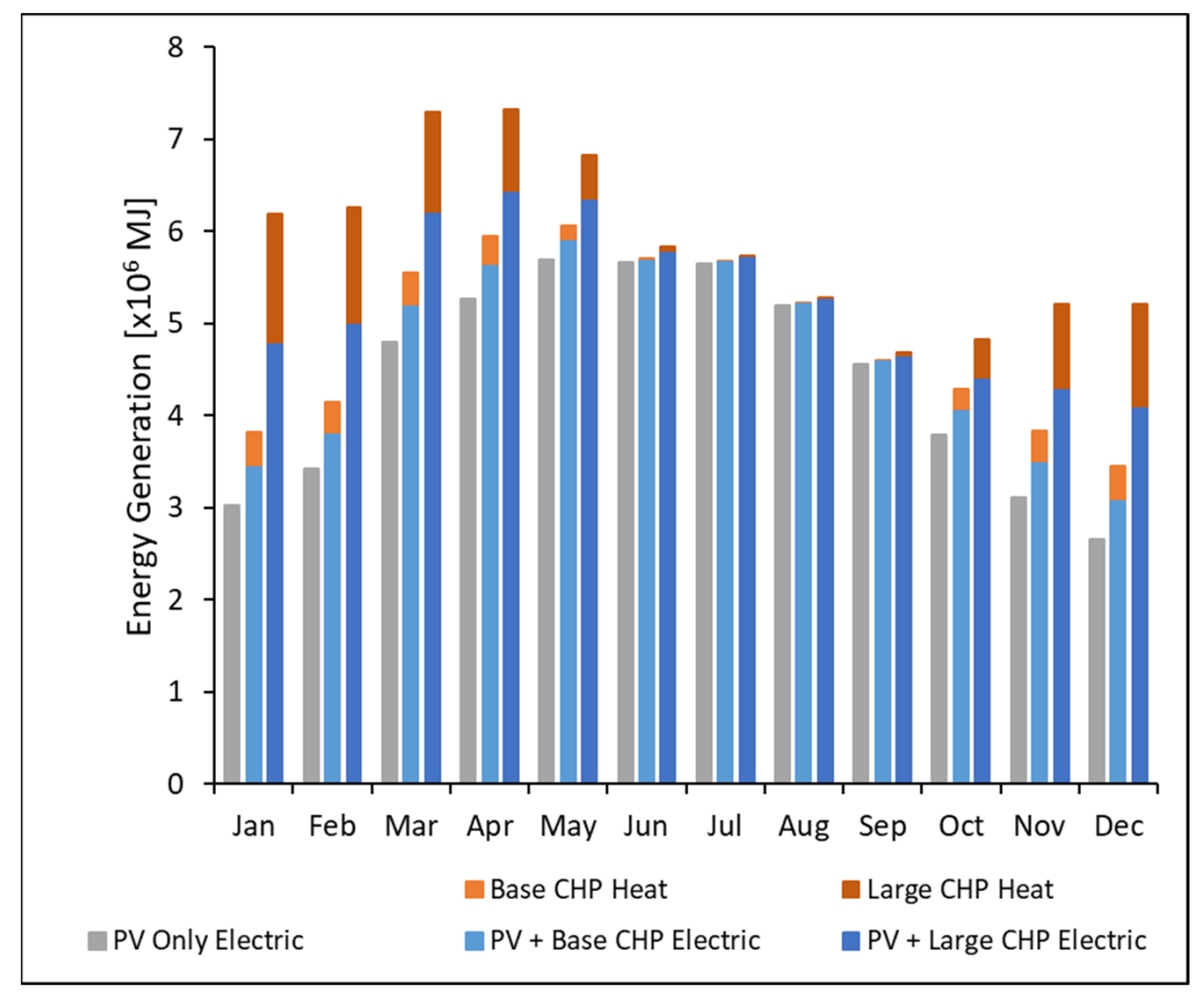

Figure 3. NWC Renewable Energy Generation by month. PV generation is the baseline for the campus and supplemented with either the base or large CHP technology. Heat energy is differentiated by color. $\mathrm{CHP}$ on/off duty operation is determined based on hourly heating load requirements. The resultant base CHP system operates at $72 \%$ of annual capacity. The large CHP is throttled in increments of $25 \%$ proportional to the $2 \times$ Summer heating load. The operational duty result is $55 \%$ of annual capacity.

\subsection{Energy Storage and Balance}

A net-zero energy analysis is conducted on a total annual energy basis. The Normal and $2 \times$ Summer load profiles are matched with PV, Heat Pump, and CHP renewable energy generation to create six unique energy load/generation scenarios: Normal PV only, Normal HP, Normal CHP, $2 \times$ Summer PV only, $2 \times$ Summer HP, and $2 \times$ Summer $\mathrm{CHP}$, where the HP and CHP scenarios also include PV. Table 2 summarizes the annual net energy for each of the six scenarios, separating load and generation into electric and natural gas (heat) and summing the total annual energy. PV alone is insufficient to achieve a net-zero energy campus. However, combining PV with either HP or CHP technologies does enable three net-zero energy scenarios: Normal HP, Normal CHP, and $2 \times$ Summer CHP. All of these achieve similar levels of net-zero energy status as indicated in Table 2 where the total generation/load ratio exceeds $100 \%$.

For the Normal campus energy load profile, PV paired with HP or CHP is able to achieve net-zero energy status. The $10 \%$ reduction in energy load enabled by HP technology brings the total energy load below the $53 \times 10^{6} \mathrm{MJ}$ estimated generation capacity of the campus-wide PV such that the PV generation is now $104 \%$ of the load. The reduced natural gas load enabled by the HP technology is offset with excess generated PV electricity to achieve net-zero energy. With the base CHP energy generation, the PV plus CHP generated energy is 103\% of the campus energy load due to additional CHP generated energy. In this case, the net natural gas load is reduced by the CHP generated heat, and the combination of excess PV and CHP generated electricity exceeds the net natural gas load. 
Table 2. NWC annual energy load and generation. Renewable energy scenarios incorporate PhotoVoltaic (PV), Heat Pump $(\mathrm{HP})$, and Combined Heat and Power (CHP) technologies. Load and generation are listed as electric and natural gas (heat) in addition to total. Three of the six scenarios achieve net-zero energy status as indicated by the parenthesized negative annual net-energy and a total generation/load ratio greater than $100 \%$. Net-zero energy is achieved through producing an excess of electricity to offset net natural gas load.

\begin{tabular}{|c|c|c|c|c|c|c|c|}
\hline & & \multicolumn{2}{|c|}{ PV Only } & \multicolumn{2}{|c|}{ PV/HP } & \multicolumn{2}{|c|}{ PV/CHP } \\
\hline \multicolumn{2}{|c|}{ Load Profile } & Normal & $2 \times$ Summer & Normal & $2 \times$ Summer & Normal & $2 \times$ Summer \\
\hline Annual & Electric & 44 & 54 & 45 & 55 & 44 & 54 \\
\hline Load & Natural Gas & 13 & 14 & 5.5 & 6.0 & 13 & 14 \\
\hline$\left[\times 10^{6} \mathrm{MJ}\right]$ & Total & 57 & 67 & 51 & 61 & 57 & 67 \\
\hline Annual & Electric & 53 & 53 & 53 & 53 & 56 & 63 \\
\hline Generation & Heat & - & - & - & - & 2.7 & 7.9 \\
\hline$\left[\times 10^{6} \mathrm{MJ}\right]$ & Total & 53 & 53 & 53 & 53 & 58 & 71 \\
\hline Annual & Electric & (9.3) & 0.9 & $(7.7)$ & 2.4 & (12) & $(9.0)$ \\
\hline Net-Energy & Natural Gas & 13 & 14 & 5.5 & 6.0 & 10 & 5.7 \\
\hline$\left[\times 10^{6} \mathrm{MJ}\right]$ & Total & 3.7 & 15 & $(2.2)$ & 8.4 & $(1.8)$ & $(3.2)$ \\
\hline \multicolumn{2}{|c|}{ Total Generation/Load Ratio } & $94 \%$ & $78 \%$ & $104 \%$ & $86 \%$ & $103 \%$ & $105 \%$ \\
\hline
\end{tabular}

For the $2 \times$ Summer campus energy load, the only renewable energy technology combination that can achieve net-zero energy status is PV plus CHP. The increased electric load of $2 \times$ Summer scenarios eliminates the excess PV electric generation seen in the Normal load scenarios, such that the $2 \times$ PV only and $2 \times$ Summer HP scenarios are not able to achieve net-zero energy. To offset the $19 \% 2 \times$ Summer load increase, the large CHP capacity is required. As evident in Figure 3, the large CHP operational duty is limited from June through September when heat demand is low, but then significantly increased all other months. The CHP is run at the highest throttle to meet the hourly heating load, with the rationale to maximize the return-on-investment for the CHP capital expenses. The resulting annual generation/load ratio is $105 \%$ meaning that annual operational duty could be reduced and still maintain net-zero energy status.

Combining the campus load profiles of Figure 2 with the campus generation profiles of Figure 3, a net energy monthly load plot can be generated, as shown Figure 4. A negative net load indicates a surplus of generated electricity exported to the grid. Figure $4 \mathrm{~A}$ shows the Normal PV only, HP, and CHP scenarios where the base CHP is applied. Figure 4B shows the $2 \times$ Summer PV only, HP, and CHP scenarios where the larger CHP system is applied. At the right of each plot, the annual sum is included. The monthly net load plot reveals significant energy-generation shortfalls in December, January, and February for all scenarios. Comparing plots A and B of Figure 4 , the $2 \times$ Summer increased load reverses the excess electric generation (negative net load) of June, July, and August such that there is now a small positive net load in those months. Also evident in Figure $4 \mathrm{~B}$ is that the $2 \times$ Summer CHP operational duty could be reduced significantly in March and April and still achieve net-zero energy on an annual basis.

While achieving net-zero energy status as measured by annual net energy load is a beneficial design goal and accomplishment, it does not capture the full infrastructure impact of the campus energy design as energy flows to and from the grid. The three scenarios that achieve net-zero energy status do so by generating excess electricity. Furthermore, since most of the electricity is generated by PV, excess electricity will be generated during the day with a shortfall of electricity each night. Thus, electricity is exported to the grid during the day, and imported to meet load at night. From an energy accounting point of view, the grid acts as near-infinite-capacity energy storage. While total energy load can be satisfied in this manner, the load/generation balance dynamics and economics of energy flow to and from the grid can benefit from local on-site storage in the form of Li-ion battery technology. 


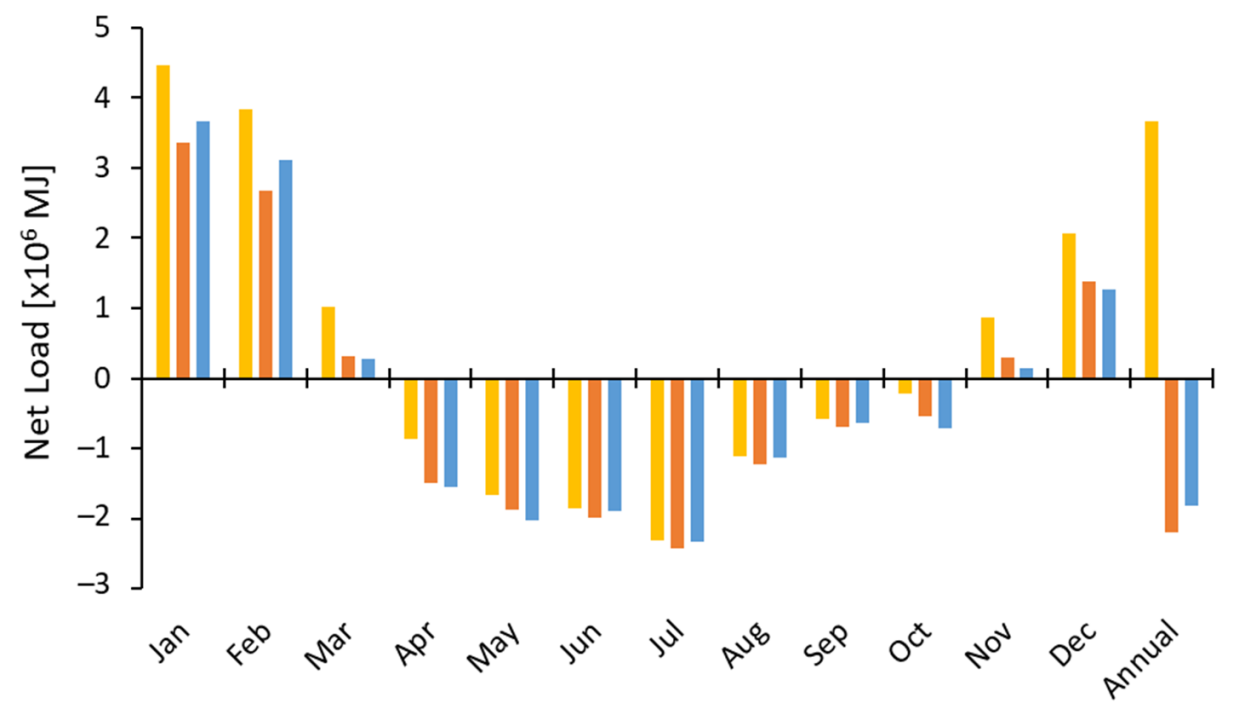

(A)

Normal PV only $\quad$ Normal HP $\quad$ Normal CHP

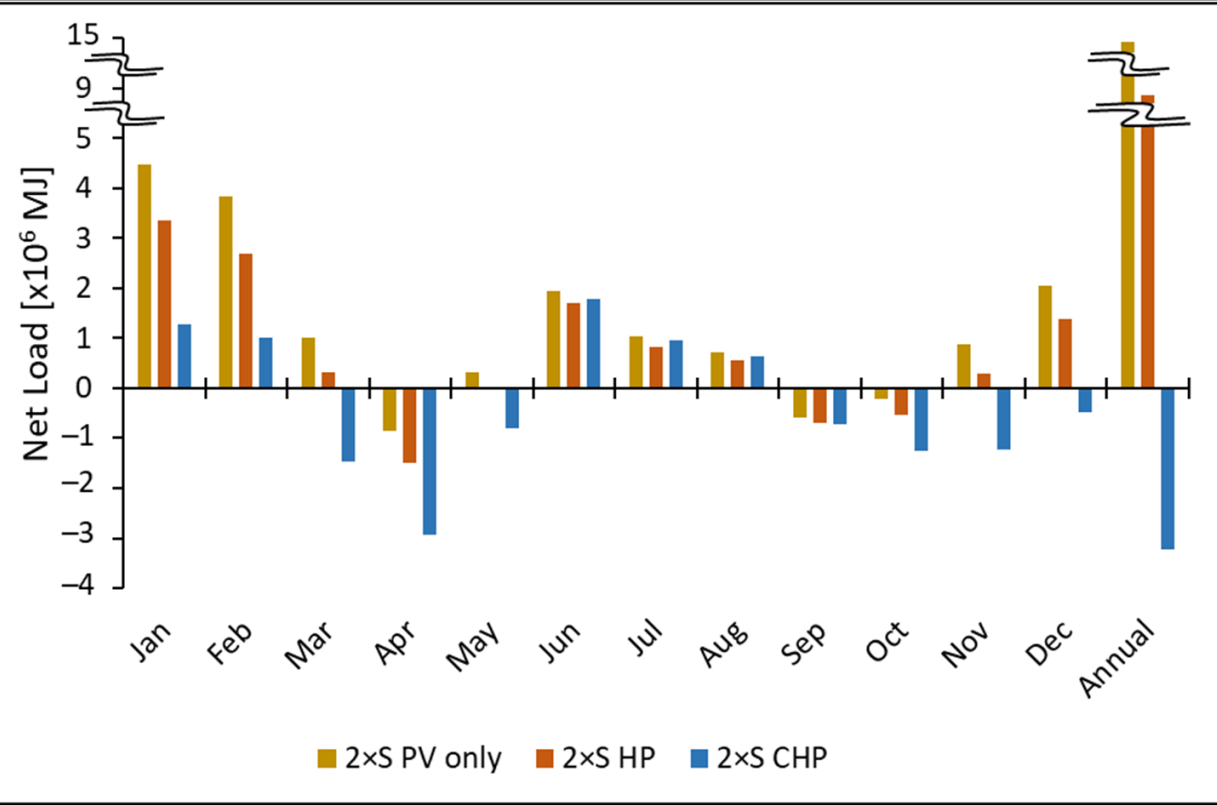

Figure 4. NWC monthly net load for each load/generation scenario. Negative load values indicate a surplus of energy generation. Plot (A) is Normal load with PV only, Heat Pump (HP), and base CHP generation scenarios. Plot $(\mathbf{B})$ is $2 \times$ summer $(2 \times \mathrm{S})$ load with PV only, HP, and large CHP generation scenarios. The net annual load is included at the far right, which is negative for the scenarios that achieve net-zero energy.

The impact of on-site storage is investigated by summing the flow of electricity on an hourly basis. Generated electricity distribution is prioritized to first offset load, second charge the battery, and third export to the grid if the battery is already fully charged. Electric load is first met by generated electricity, second by energy stored in the battery, and third by imported electricity from the grid. The analysis is repeated for various battery storage capacities to generate the plots shown in Figure 5. The separate plots of imported and exported electricity fraction are normalized by the total electric load and generation, respectively, for each energy scenario. The impact of storage on the cumulative load and generation is substantial, cutting the total grid dependence approximately in half. 

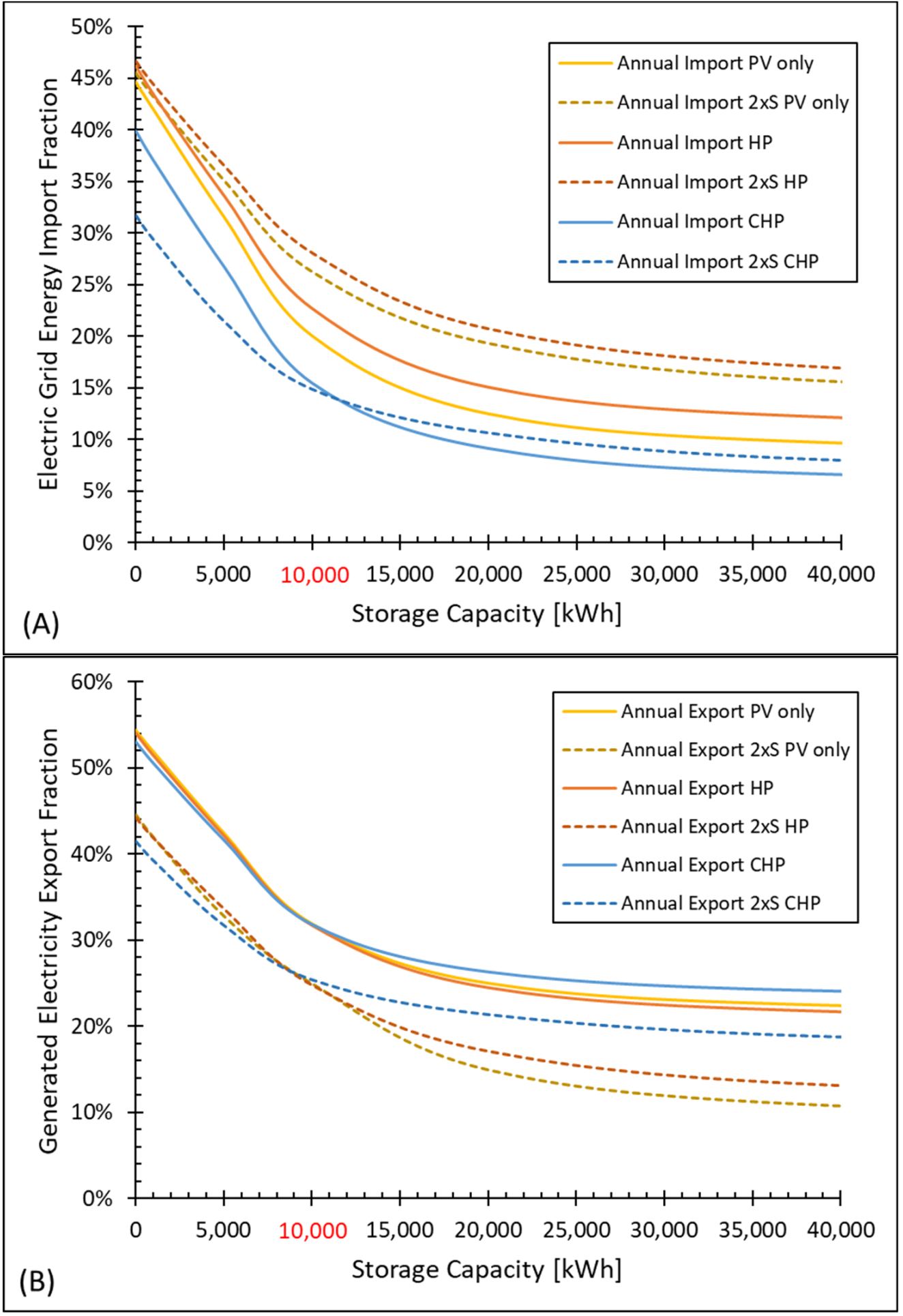

Figure 5. Effect of storage capacity. Plot (A) displays the imported grid electricity as a fraction of total electric load. The CHP scenarios import the smallest fraction of electricity while the $2 \times$ Summer $(2 \times$ S) load scenarios generally increase the fraction of imported electricity. Plot (B) displays the exported electricity as fraction of total generation. The $2 \times \mathrm{S}$ scenarios reduce export fraction most significantly due to alignment of peak summer load and peak PV generation. Increased storage reduces import and export fractions in all scenarios, with an effect that is greatest at smaller storage capacities. A levelized cost optimal 10,000 kWh of storage was assumed in the analysis. 
Figure $5 \mathrm{~A}$ plots the electric grid energy contribution (i.e., import), which is reduced from $30-45 \%$ to $15-25 \%$ with $10,000 \mathrm{kWh}$ of storage. This amount of storage is determined later in the analysis to be a cost-optimal amount of storage representing approximately $30 \%$ of the annualized daily electric load. Even so, Figure 5 indicates that additional storage can reduce the grid energy import even more. This room for additional grid independence improvement is where collaborating agreements between NWC and the local utility could be used to increase the energy benefit by implementing storage capacities higher than merely the optimized campus cost capacity.

Figure $5 \mathrm{~B}$ plots the generated electricity export fraction. Again, the impact of storage is significant, reducing the export fraction from $40-55 \%$ down to $20-33 \%$. Unlike the import fraction, which falls to below $10 \%$ in some scenarios, the export fraction remains higher for most scenarios owing to the excess generated electricity used to achieve net-zero annual energy. Unfortunately, the lowest export fraction scenarios ( $2 \times$ Summer PV only and HP) do not achieve net-zero energy. Two other noteworthy items can also be seen on the figure. The first is that exported energy is reduced in all $2 \times$ Summer cases. Secondly, there is a minimum to which the PV export electricity fraction can be reduced with storage $(\sim 26 \%$ for Normal, $\sim 12 \%$ for $2 \times$ Summer), at which point the storage has resolved the hourly and daily energy mismatch, leaving behind the seasonal mismatch of generated electricity.

In order to measure and compare the total infrastructure impact of the various NWC energy scenarios, a load match calculation is conducted on an hourly, per carrier basis [42]. In the NWC analysis, the carriers are natural gas and electricity. A positive hourly net energy load on each carrier is counted as positive net load, while negative net energy load is considered positive net generation. The hourly net generation is cumulatively summed and plotted versus the cumulatively summed hourly net load as shown for each scenario in Figure 6. The summed net load is energy (electric and natural gas) that must be imported from the grid and the summed net generation is excess electricity to be exported to the grid.

There are two key results on display in Figure 6. The first key result is that if the trace of cumulative hourly summed energy ends above the dashed line, then net-zero energy status has been achieved on an annual basis. The further the end point is above this dashed line, the greater the net-zero energy margin. The second key result is the distance from the trace end point to the plot origin $(0,0)$. This distance is a measure of impact on the energy infrastructure in terms of energy flow to and from the grid. Of the three energy scenarios that achieve net-zero energy status, the $2 \times$ Summer CHP is the closest to the origin and has the lowest net energy load sum. Further inspection of the $2 \times$ Summer CHP scenario (see Figure 4) indicates that throttling could be reduced in spring and fall months to reduce the net energy-generation sum and infrastructure impact of electricity export to the grid further.

Figure 6A plots the six energy scenarios, showing that Normal HP, Normal CHP, and $2 \times$ Summer CHP all achieve net-zero energy. Figure 6 B includes $10,000 \mathrm{kWh}$ of battery storage, and the impact is dramatic. Note that the percentages of Figure 6 where electricity and natural gas are summed separately as distinct carriers, differs from Figure 5, which plots just electricity. For the net-zero energy scenarios with storage, the cumulative net load is reduced from $40-50 \%$ down to $20-30 \%$, while the cumulative net generation is reduced from $45-55 \%$ down to $25-35 \%$. In addition to being a cost optimal solution, the implementation of battery storage has a key energy infrastructure benefit of greatly reducing the quantity of energy imported from and exported to the grid.

The fine detail results of Figures 5 and 6 are dependent on the efficiency of the battery storage. A round trip of $90 \%$ was assumed in this analysis, since it is possible to DC-couple the energy storage knowing that AC-DC-AC conversion power electronics losses are the largest contributor to storage losses $[40,50]$ and inverter losses are already included in the $\mathrm{PV}$ generation data [41]. If the round-trip efficiency is lower, then the district energy import fraction (Figure 5A) and the cumulative net load fraction (Figure 6) will both increase as energy is lost due to storage inefficiency. These combined effects lower the net-zero energy margin, as evident in the cumulative traces of Figure 6 ending closer to the net-zero 
energy boundary line. The net-zero energy impact is tempered by the fact that storage inefficiencies do not impact the generated energy that directly offsets district load. For the levelized cost results in the following section, the impact of these percentage energy losses is minor in comparison to the buy:sell ratio of 3 that economically incentivizes storage.
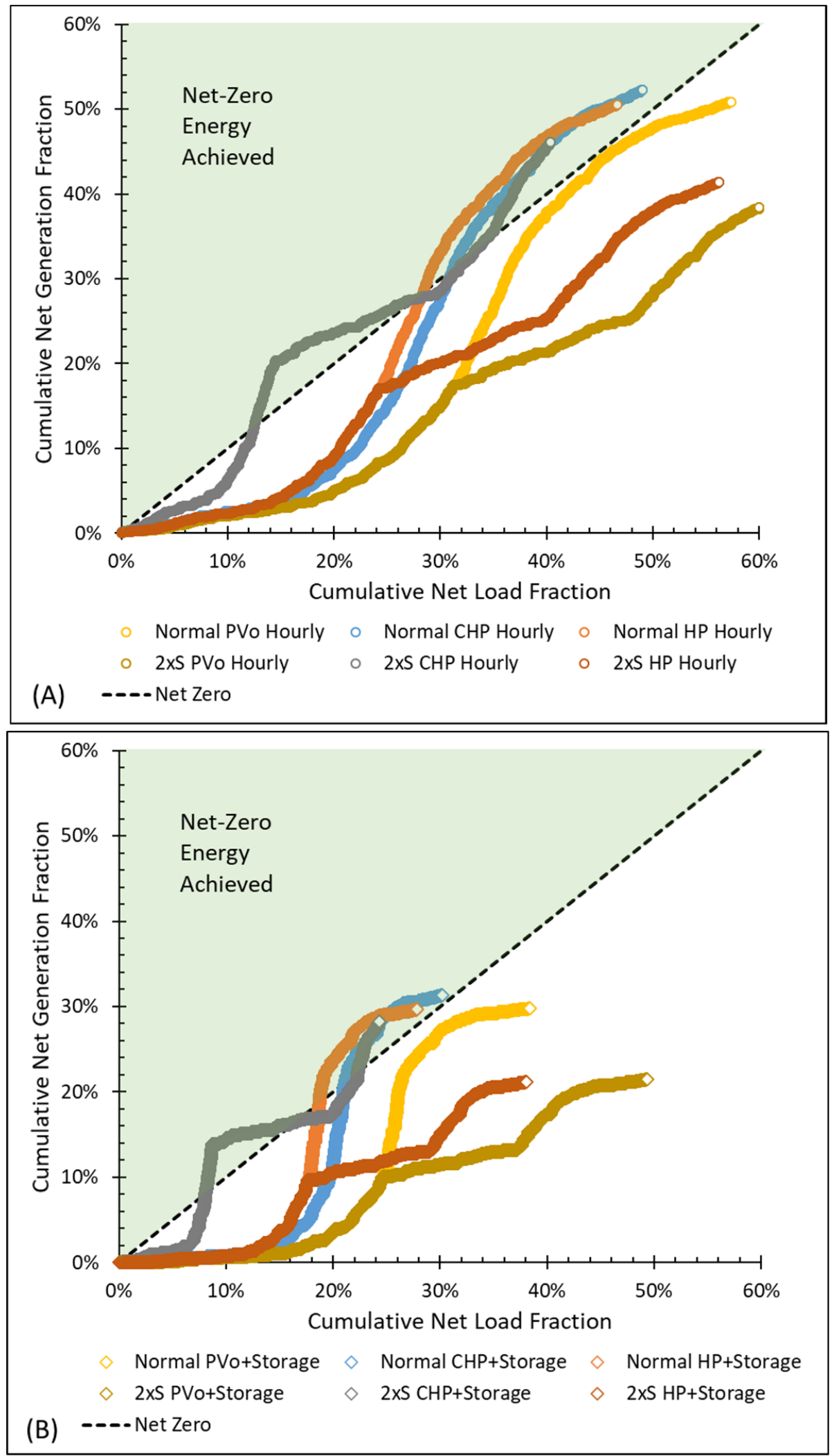

Figure 6. NWC cumulative net load/generation plots. Data of each scenario is summed hour-to-hour 
separately for each carrier (natural gas and electric) based on whether the net energy demand is positive (net load) or negative (net generation). Plot values are normalized as a fraction of total annual load and generation for PV only (PVo), PV / HP, and PV/CHP with both Normal and $2 \times$ Summer $(2 \times S)$ loads. Plot $(\mathbf{A})$ is the six baseline energy scenarios while plot $(\mathbf{B})$ includes energy storage. The cumulative traces sum the dynamic energy flow to and from the grid and demonstrate a heavy dependence on the grid for all scenarios. A final position above the net-zero dashed line indicates net-zero energy status has been achieved on an annual basis. The farther the end point is above the dashed line, the greater the net-zero energy margin. The farther the final point from the plot origin $(0,0)$, the greater the energy infrastructure dependence. Implementing $10,000 \mathrm{kWh}$ of electrical storage ( $\sim 30 \%$ of average daily load) cuts the grid interaction/dependence in half for both net generation exported energy and net load imported energy.

\subsection{Levelized Cost of Energy}

Up to this point, all energy analysis has been conducted on a built-out campus with full energy loads offset by full renewable energy-generation capacity. However, the NWC rejuvenation is a multi-year phased process, so adding a temporal component to the analysis is important. To compare the energy scenarios capable of achieving net-zero energy status, a LCOE calculation is made based upon phased 30-year energy profiles and the economic parameter assumptions outlined in Section 2.4. The first ten years of the analysis features five discrete steps of increasing annual energy load as new buildings are added (see Figure A3). The CHP technology is brought online in year 3 (phase 3). The Livestock and Equestrian buildings are brought online in years 6 and 9 (phases 4 and 5), bringing with them a large PV generation capacity, such that net-zero energy status is achieved in year 10. Storage is added in two equal capacity halves in phases 4 and 5. LCOE is calculated as the energy cost to achieve a zero Net Present Value (NPV) for the capital and operating expenses distributed over the 30-year analysis.

The LCOE calculation enables investigation and economic optimization of model parameters and assumptions. Figure 7 presents the LCOE as a function of storage capacity. The nominal buy:sell ratio of 3 is plotted, as well as the much less favorable ratio of 100 . Only the three net-zero-energy-achieving scenarios are included in the plot. A storage capacity of 10,000 kWh represents a near cost-optimal amount for all three energy scenarios and both buy:sell ratios. Storage has a greater benefit with a higher buy:sell ratio, while the $2 \times$ Summer CHP is least sensitive to storage owing to the better overall match between load and generation. Despite the energy benefit of increased storage capacity noted in Figure 6, optimization of LCOE keeps the storage quantity near the 10,000 kWh assumed in the analysis.

The cost-optimal amount of storage is impacted by the frequency of its use and the temporal resolution of the pricing structure. The optimal amount of storage would likely change if a more complicated time-of-use electricity pricing structure were implemented. At $30 \%$ of the annualized daily electric load, the $10,000 \mathrm{kWh}$ storage fits the typical profile of PV electricity generated and stored during the day to be used that night. Figure 7 also shows that in most scenarios, doubling the storage to $20,000 \mathrm{kWh}$ is still more cost effective than no storage at all. In this case, additional energy is being stored on very sunny days to be used for future cloudy ones. Because the frequency of these weather transitions is less than the daily diurnal cycle, the economic value of the storage is diminished. Finally, Figure 7 shows that the economic value of storage continues to decrease with increased storage capacity. While there remains energy benefit to storage on this scale, the low frequency of use cannot effectively make up the additional capital cost investment. 


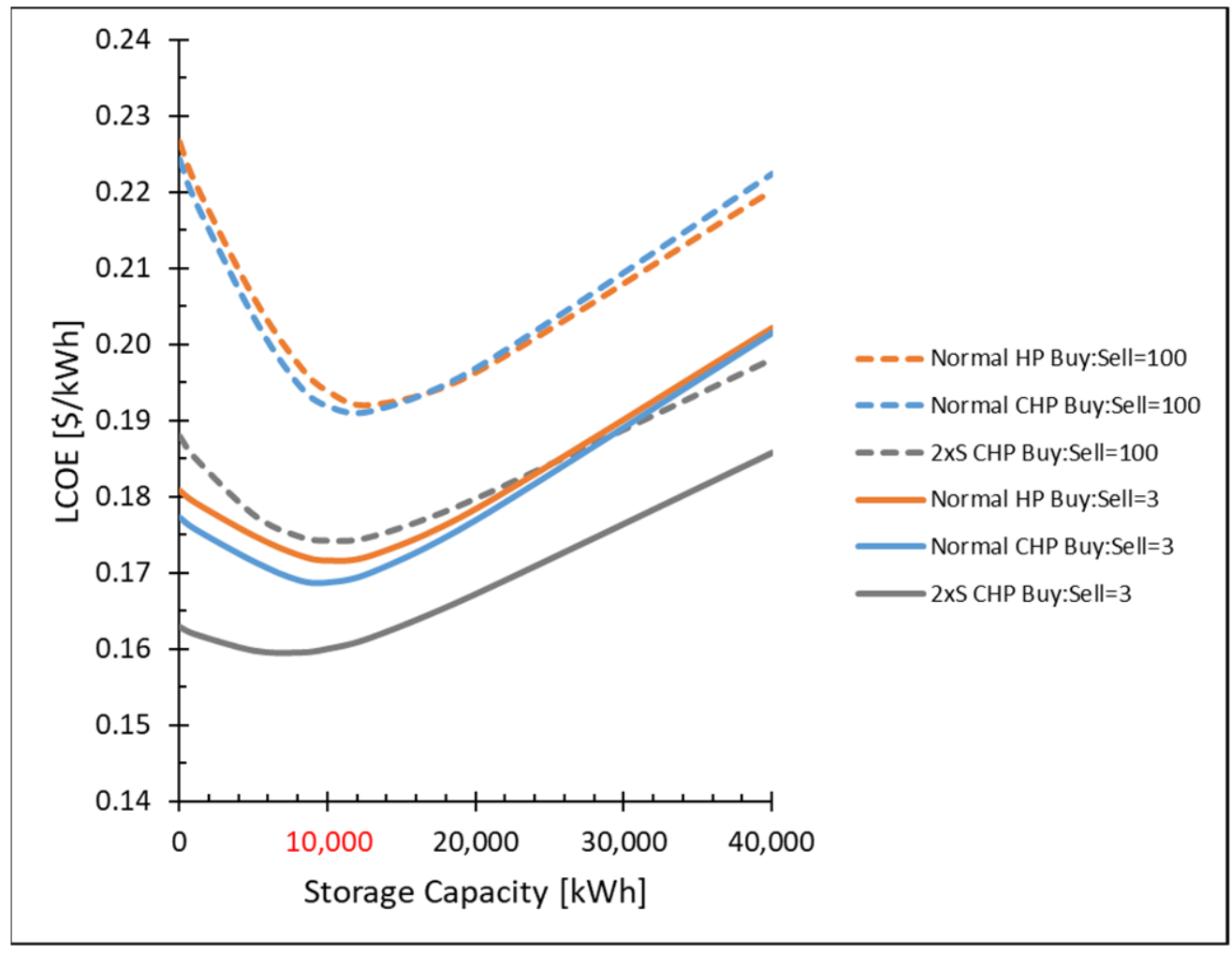

Figure 7. Levelized cost of electricity (LCOE) as a function of storage. Results are plotted for net-zero energy scenarios with buy:sell ratio traces of 3 and 100. For all scenarios and buy:sell ratios, the levelized cost optimized storage capacity is near 10,000 kWh ( 30\% of annualized daily electric load), which is the capacity assumed in the remainder of this analysis.

The economic value of storage is heavily influenced by the buy:sell ratio. With the assumed buy:sell ratio of 3 , the value of exported electricity is only one-third the cost of imported electricity. However, if the same three $\mathrm{kWh}$ could instead be stored in a battery and later used to offset load rather than import energy, then they retain the same value as imported electricity, less the efficiency losses of storage. This energy retained value benefit increases and decreases in proportion to the buy:sell ratio. When the buy:sell ratio is one (net metering), then stored energy has no additional economic value at all.

Figure 8 investigates the impact of buy:sell ratio on LCOE for the net-zero energy scenarios with and without storage as a function of buy:sell ratio. At a buy:sell ratio of one (net metering), no storage achieves the lowest overall LCOE between 0.12 and $0.13 \$ / \mathrm{kWh}$. The minimum LCOE with storage is nearly $0.14 \$ / \mathrm{kWh}$ at a buy:sell ratio of one. A crossover in LCOE occurs between buy:sell ratios of 1 and 3, such that at higher buy:sell ratios, energy storage yields a lower LCOE. This difference levels off and is most pronounced at buy:sell ratios of 100 or higher. At this extreme, storage reduces the Normal HP and CHP LCOE from 0.22 to $0.19 \$ / \mathrm{kWh}$, and the $2 \times$ Summer CHP from 0.19 to $0.17 \$ / \mathrm{kWh}$. The buy:sell ratio of 3 assumed in this analysis was based on a comparison of retail and wholesale electricity prices [51,52].

The impact of the buy:sell ratio on LCOE captures the importance of the grid for net-zero energy economic feasibility. This grid dependence can be further demonstrated by taking the energy analysis to an extreme and determining what it would take to achieve net-zero energy independent of the grid (micro-grid). From an energy point-of-view, the hourly energy balance (including storage) must always yield a zero or negative net load, as there cannot be an energy shortfall. One way this can be carried out is to add enough storage to overcome the seasonal mismatch of PV electric generation. For NWC, this would require 1.36 million $\mathrm{kWh}$ of battery storage, a capital investment of $\$ 340$ million, and a resulting LCOE of $1.77 \$ / \mathrm{kWh}$. In essence, this enlarged capacity is storing peak summer 
generated electricity to use in the winter where the generated electricity is less than the load. The annual frequency of storage use in this situation is very low, and results in an LCOE that is ten times higher than that achieved when connected to the grid.

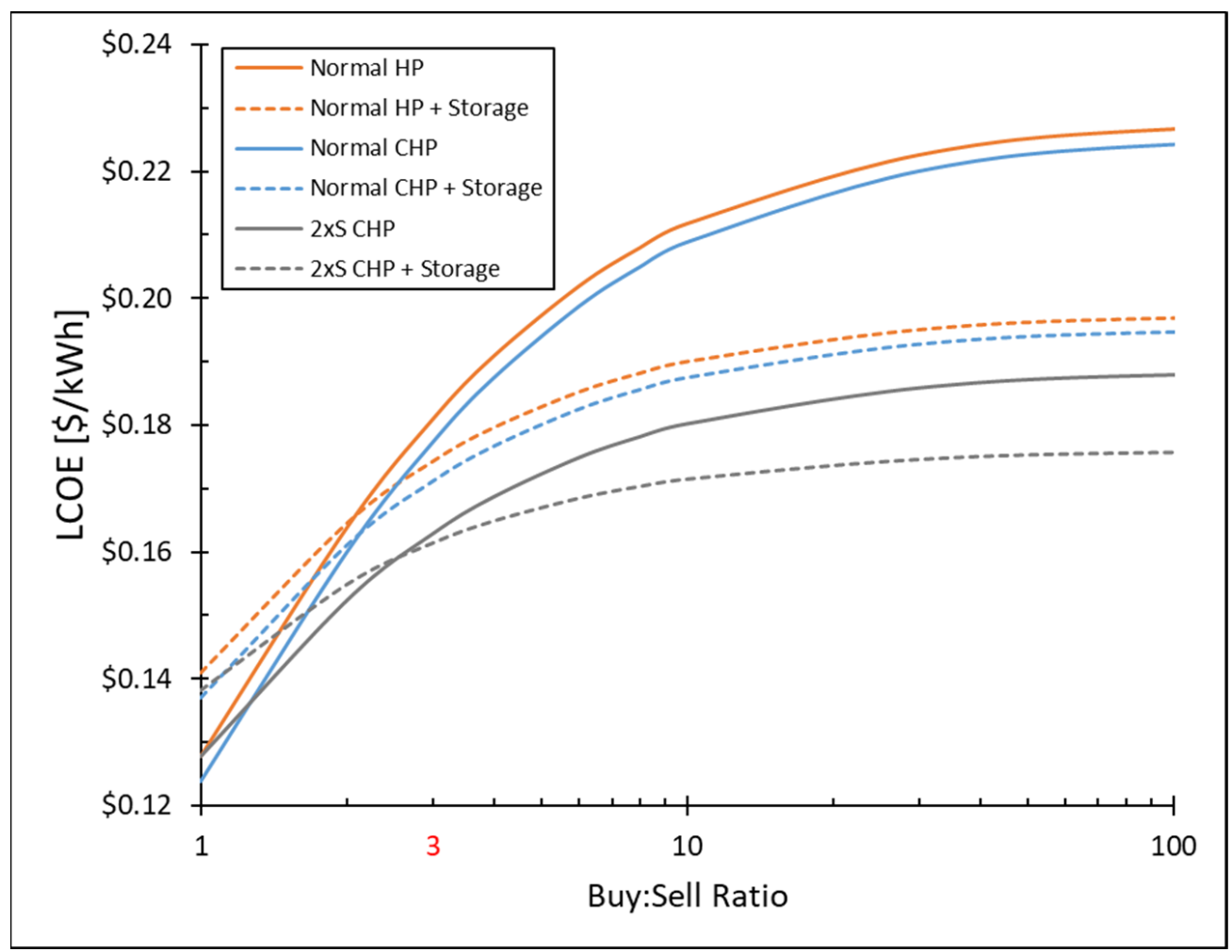

Figure 8. Levelized Cost of Electricity (LCOE) with and with without storage. Only net-zero energy scenarios are plotted. A buy:sell ratio of 1 is net metering where the results cluster with their minimum LCOE near $0.14 \$ / \mathrm{kWh}$ and $0.13 \$ / \mathrm{kWh}$ with and without storage, respectively. As the buy:sell ratio increases, scenarios with storage achieve a lower LCOE. The cross-over buy:sell ratio is between 1 and 2 for the normal load profiles, and just over 2 for the $2 \times$ Summer $(2 \times S)$ CHP net-zero energy strategies. A nominal buy:sell ratio of 3 was assumed in this analysis based on a comparison of wholesale and retail electricity prices [51,52].

A second method to achieve a micro-grid is to increase the PV generation capacity. The winter seasonal shortfall in electricity can be met with an additional $8500 \mathrm{~kW}$ of PV capacity, but storage must also be increased to 120,000 $\mathrm{kWh}$ (about three days of winter load) to meet all the energy load. The result is an additional $\$ 45$ million in capital, resulting in a LCOE of over $0.33 \$ / \mathrm{kWh}$. While this cost is much better than the storage-only micro-grid approach, the LCOE is twice that of the grid-dependent net-zero energy scenarios. Clearly, the grid is an important factor in the economic feasibility of net-zero energy districts.

The LCOE of the three net-zero energy scenarios is shown in Figure 9, subdivided into categories of capital expenditures (equipment and facilities), operating costs, and taxes; and further broken down to reflect the portion from each renewable energy source. The cost is reported per kWh of energy since this is a metric more intuitively understood and typically reported for PV energy generation. As a cost point reference on the plot is the average electricity from NWC utility bills of $0.105 \$ / \mathrm{kWh}$, in agreement with electricity prices reported by the U.S. Energy Information Administration [51]. Since the economic analysis is built on an IRR of 5\%, comparing to these utility rates is not directly applicable, but they do represent an evaluative benchmark for the renewable energy technologies, nonetheless. Also included on the plot is the $0.33 \$ / \mathrm{kWh}$ additional PV and storage micro-grid calculated result. 


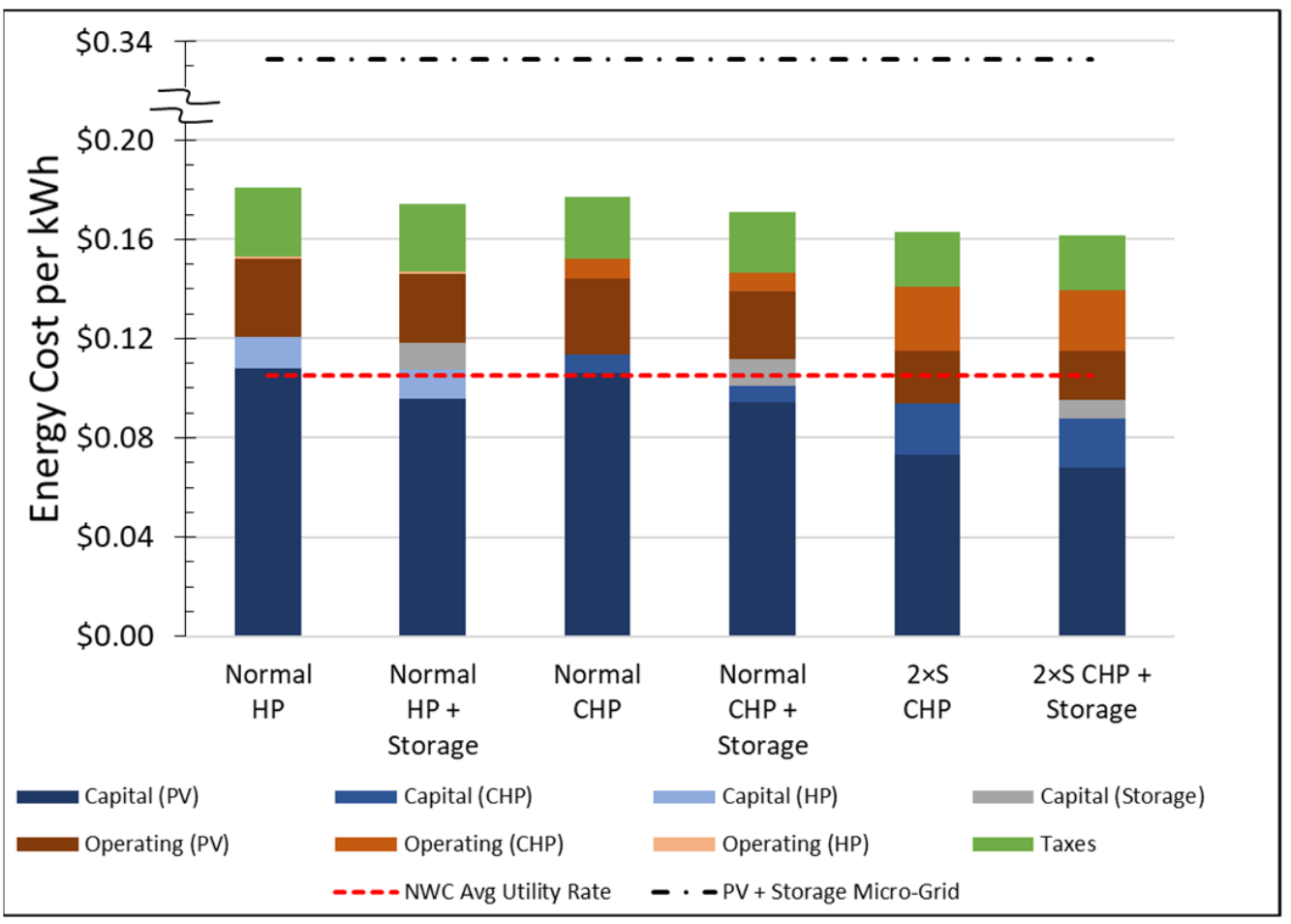

Figure 9. Net-zero energy Levelized Cost of Energy (LCOE) breakdown and comparison. CHP scenarios result in lower LCOE due to better winter (December, January, February) load matching and lower per energy generation capital cost. The $2 \times$ Summer $(2 \times \mathrm{S}) \mathrm{CHP}$ is the lowest LCOE benefiting from better summer (June, July, August) load/generation matching. The impact of storage is minimal with the buy:sell ratio of 3 assumed in the analysis. The best net-zero energy LCOE is just above $0.16 \$ / \mathrm{kWh}$, which is considerably higher than the average retail electricity rate paid by NWC $(0.11 \$ / \mathrm{kWh})$, but much lower than the PV + storage micro-grid $(0.33 \$ / \mathrm{kWh})$, both of which are included on the plot for comparison.

The CHP energy scenarios achieve the lowest LCOE values in large part because of their no-cost waste stream sources, with modest fuel processing costs assumed in the operating expenses. It is possible that these $\mathrm{CHP}$ operating expenses could increase significantly based on the condition of the source fuel. The CHP LCOE is also lower due to its inherent combined electricity and heat energy benefit, and the fact that its dispatchable output can be better matched to NWC's winter heavy energy load. Despite the lower operational duty of the large CHP, the $2 \times$ Summer CHP energy scenario results in the lowest LCOE due to a better match of increased summer load with summer peak PV energy generation. The LCOE was observed to be reduced in all $2 \times$ Summer scenarios for this same reason. The LCOE of all six scenarios is increased due to taxes, loan interest, buy:sell ratio, and the 9-year period over which the PV modules are installed.

Despite the heavy reliance on PV electricity to achieve net-zero energy, the LCOE results of this analysis are significantly higher than other published PV LCOE published values [25]. This is largely due to the exclusion of capital tax incentives, an IRR greater than historical inflation, and the buy:sell ratio. In addition to these differences in economic modeling, the NWC has less than optimal PV output due to campus building and roof orientations. A south facing ( $180^{\circ}$ azimuth), $40^{\circ}$ tilt $\mathrm{PV}$ system is expected to generate over $1600 \mathrm{kWh} / \mathrm{kW}$ per year, while the area-weighted average output of the NWC PV analysis is just over $1400 \mathrm{kWh} / \mathrm{kW}$.

With the buy:sell ratio of 3, the Normal HP, Normal CHP, and $2 \times$ Summer energy scenarios all achieve a lower LCOE with the $10,000 \mathrm{kWh}$ battery storage. The range of LCOE of all three is close, between $0.16 \$ / \mathrm{kWh}$ and just over $0.17 \$ / \mathrm{kWh}$. As can be observed in Figure 9, these values are all significantly higher than NWC's retail rate of 
conventional grid electricity at less than $0.11 \$ / \mathrm{kWh}$. However, these LCOE values are substantially lower than the best micro-grid scenario $(0.33 \$ / \mathrm{kWh})$, which emphasizes the critical role played by the grid in the economic feasibility of net-zero energy districts. It is important to also acknowledge benefits not captured in this analysis such as $\mathrm{CO}_{2}$ reduction, urban design, and quality of life, which all factor into NWC's sustainability objectives and its initiation of a net-zero energy goal. Indeed, factors like these are often leveraged in the creation of government capital investment tax incentives and feed-in-tariffs (buy:sell $<1$ ) to make up the existing LCOE difference observed in this analysis.

The LCOE advantage of storage energy scenarios is also significant to the role of the grid in net-zero energy districts. Storage is a benefit to NWC in terms of LCOE, as well as to the grid in terms of dynamic flow and energy dependence. Storage has also been demonstrated to be important to grid stability in a sub-hourly power analysis [8]. The buy:sell ratio of this analysis is an initial quantification of the important relationship between the grid and the net-zero energy district. Design and development in concert with the local utility is one area emphasized in public-private partnerships of the ZEDA initiative. Indeed, future work on this front can explore the impacts and optimization of storage with time-variant electricity prices and other possible grid stability pricing and capital incentives. These are likely to play out somewhat differently for each net-zero energy district under consideration and thus it is important to partner and collaborate early in the district energy development.

\subsection{Sensitivity Analysis}

Sensitivity analysis results of the LCOE model for the three scenarios achieving netzero energy status are shown in Figure 10. For the eleven model parameters (ten degrees of freedom) with a 0.05 significance level ( $95 \%$ confidence) on a two-tailed distribution, the critical $t$-value is 2.23 and marked as a dashed line in Figure 10.

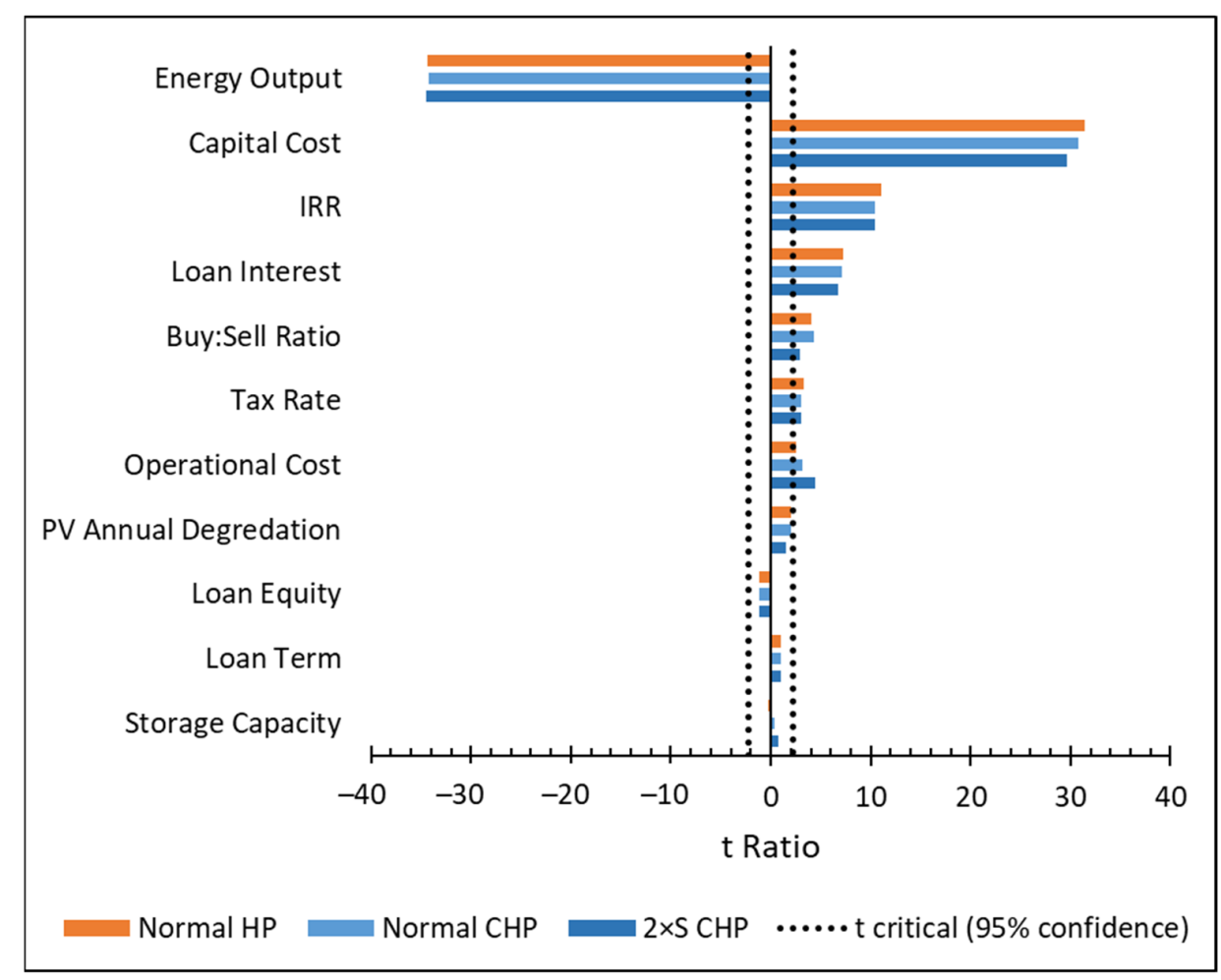

Figure 10. LCOE sensitivity analysis. Results are based on a $\pm 10 \%$ change in each parameter. While energy output, capital cost, IRR, and loan interest are the most sensitive in effecting a change in LCOE; buy:sell ratio, tax rate, and operational cost are also statistically significant for all three net-zero energy scenarios. Storage capacity has the least significant impact on LCOE because a cost optimal amount of storage was used in the analysis. 
As expected, energy output and capital costs have the highest impact, with the energy output being negative because an increase in energy output decreases the LCOE. Time value of money parameters (IRR and loan interest) also rank high on impacting results, while buy:sell ratio, tax rate, and operational cost are also statistically significant. Large changes in the assumed values of these parameters will significantly impact the LCOE results. The sensitivity analysis also indicates the operational cost impact is relatively more important in the CHP scenarios where operating costs per $\mathrm{kW}$ are much higher than PV or heat pump. The operating cost $t$-ratio further increases for the larger $2 \times$ Summer $\mathrm{CHP}$ scenario. Thus, if fuel processing costs are significantly higher than currently estimated, the $\mathrm{CHP}$ technology will be less economically attractive. The loan term, PV annual degradation, and loan equity impacts all have statistically insignificant impacts on the LCOE results. Storage capacity appears as the least significant parameter because the $10,000 \mathrm{kWh}$ capacity assumed is near the cost optimum value for all scenarios.

\section{Conclusions}

An interesting opportunity for renewable energy penetration is the development of net-zero energy districts. The work leverages detailed building energy modeling coupled with energy-generation modeling to not only evaluate the ability for different renewable energy system configurations to meet NWC's net-zero energy target, but also quantify their economic viability and their level of grid dependence. Results show that multiple combinations of PhotoVoltaic (PV), Heat Pump (HP), and Combined Heat and Power (CHP) technologies can achieve net-zero energy status with an LCOE in the range of 0.16 to $0.18 \$ / \mathrm{kWh}$ with the assumed model parameters, and below $0.13 \$ / \mathrm{kWh}$ with net metering. The large building area and low Energy Use Intensity (EUI) Livestock and Equestrian complexes offset the high EUI impact of the Water Resource Center (WRC) and Animal Health buildings; a benefit of broadening the net-zero energy analysis to the entire campus.

Heavy deployment of PV modules on existing and new buildings is the baseline strategy to achieve a net-zero energy campus. In addition to PV electricity, on-site biomass and thermal sources can be leveraged in CHP and HP technologies, respectively, creating alternative net-zero strategies that can meet the current thermal energy load, as well as load models for future increased summer events. CHP offers a cost advantage in terms of LCOE (0.004 \$/kWh less than HP) while the heat pump has a slightly more favorable net load/generation balance (47/51\%) than CHP (49/52\%). The heat pump approach also offers a sustainability advantage in lowering the total site energy load by $10 \%$ and maintaining an energy advantage from a source perspective.

The critical role played by the grid is quantified with a buy:sell energy pricing ratio, where net metering is equal to one and feed-in tariffs are less than one. A buy:sell ratio of 3 was assumed in the analysis, in which battery storage energy scenarios gain up to a $0.009 \$ / \mathrm{kWh}$ LCOE advantage over scenarios without storage. Storage is also a benefit in terms of grid independence where the energy export and import ratios can be reduced from greater than $50 \%$ to less than $30 \%$. This coupling between district energy cost advantage and reduced grid dependence driven by the buy:sell ratio indicates that a collaborative partnership between the net-zero energy district and the local utility is key to the economic feasibility of the net-zero energy district.

This initial net-zero campus study sets the stage for future energy monitoring and net-zero energy studies as the NWC development advances. Energy models and strategies developed, employed, and validated at the NWC can be applied to buildings and campuses across the world in an effort to cultivate building and district design practices that benefit local, national, and global communities.

Author Contributions: B.A.S.: Conceptualization, Methodology, Software, Validation, Formal analysis, Investigation, Writing-Original Draft, Visualization. J.C.Q.: Conceptualization, Methodology, Resources, Writing-Review \& Editing, Visualization, Supervision, Project administration, Funding acquisition. All authors have read and agreed to the published version of the manuscript. 
Funding: This work was supported financially by the $\mathrm{CH} 2 \mathrm{M}$ Foundation and The Gates Family Foundation (log \#0202-1720) as part of a larger effort of Colorado State University's (CSU) NWC Sustainability Team.

Data Availability Statement: All data is available through the supplementary information or directly from the authors.

Acknowledgments: This work was conducted as part of a larger effort of Colorado State University's (CSU) NWC Sustainability Team. Specific thanks to Jocelyn Hittle and Colin Day for their leadership of this team. The work of Evan Sproul, Hannah Mendel, and Jack Johnson is also acknowledged in the preliminary NWC renewable energy assessment, which informed the work presented here. Finally, a thank-you to Danna Quinn for assistance with technical editing.

Conflicts of Interest: The authors declare no conflict of interest.

\section{Appendix A}

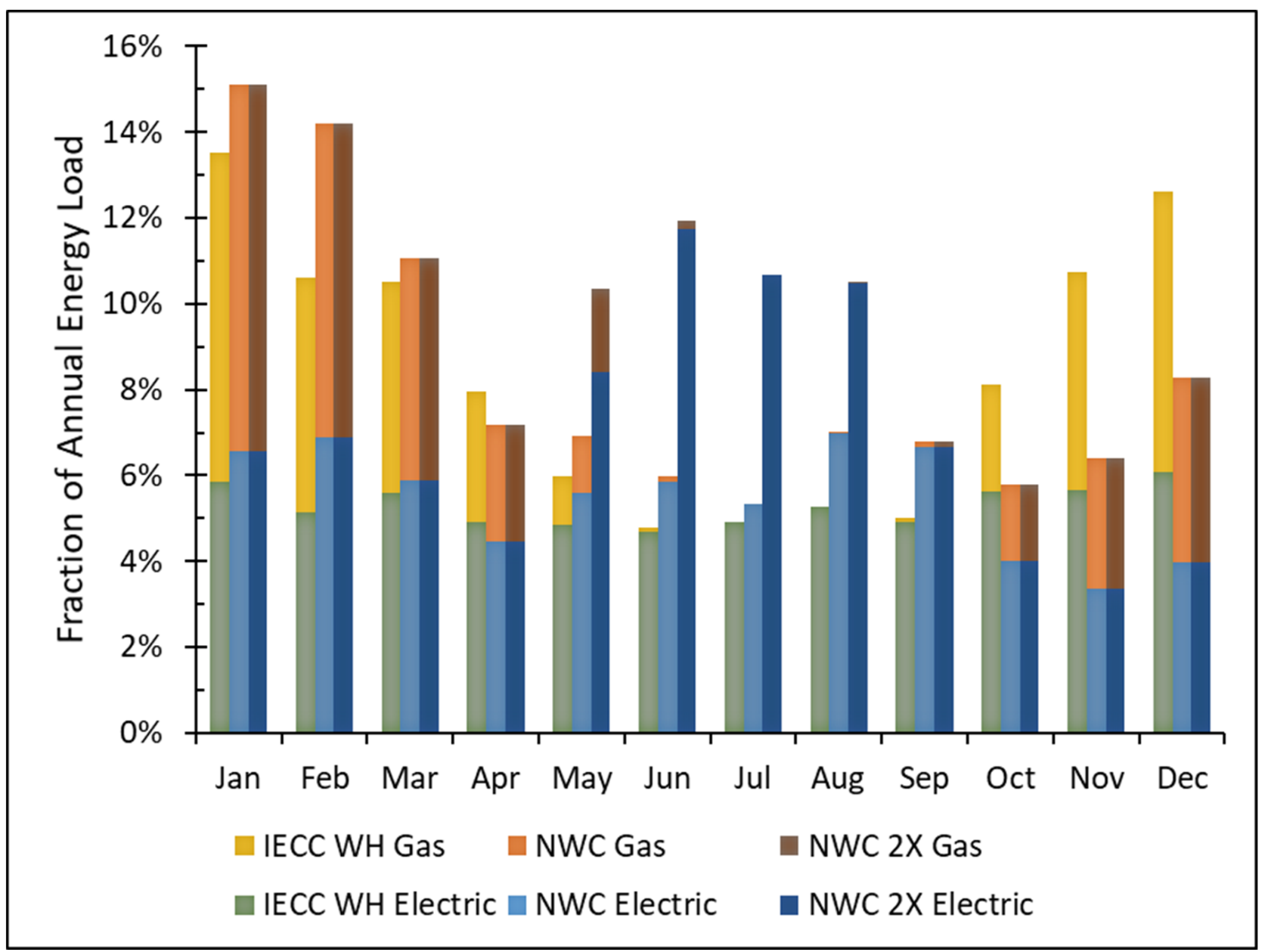

Figure A1. NWC "warehouse" building type annual load distribution profile as modified from IECC Warehouse (WH) model. NWC's load is characterized by increased winter and summer use, with decreased load in the fall. The electricnatural gas ratio shifts $64-36 \%$ IECC to $66-34 \%$ NWC. A $2 \times$ summer projected load profile results in a $20 \%$ total annual load increase (sums to $120 \%$ ) with a $70-30 \%$ electric: natural gas ratio. 
Table A1. Preliminary NWC Renewable Technology Feasibility Study Results indicating that $\mathrm{PV}$, biomass, and heat pump are the preferred on-site renewable resources to achieve a net-zero energy campus.

\begin{tabular}{cccc}
\hline $\begin{array}{c}\text { Electrical } \\
\text { Technologies }\end{array}$ & IRR & Thermal Technology & IRR \\
\hline Photovoltaics & $7 \%$ & Wastewater Heat Recovery & $-2 \%$ \\
On-Site Wind & $-3 \%$ & Biomass & $9 \%$ \\
Off-Site Wind & $17 \%$ & Solar Heating & $-13 \%$ \\
& & Ground-Source Heat Pump & $0 \%$ \\
\hline
\end{tabular}

Table A2. Summary of NWC annual energy loads. The $2 \times$ Summer profile increases total energy load by $19 \%$ over Normal. Implementing Heat Pump (HP) technology increases both the electric load and fraction of electric, but reduces natural gas load by more than half, such that the total energy load is reduced by $10 \%$ for both Normal and $2 \times$ Summer profiles.

\begin{tabular}{ccccc}
\hline & Normal & Heat Pump (HP) & $\mathbf{2} \times$ Summer & $\mathbf{2} \times$ Summer HP \\
\hline Electric Load $\left[\times 10^{6} \mathrm{MJ}\right]$ & 44 & 45 & 54 & 55 \\
Natural gas Load $\left[\times 10^{6} \mathrm{MJ}\right]$ & 13 & 5.5 & 14 & 6.0 \\
Total Energy Load $\left[\times 10^{6} \mathrm{MJ}\right]$ & 57 & 51 & 67 & 61 \\
Relative to Normal & $100 \%$ & $90 \%$ & $119 \%$ & $108 \%$ \\
Fraction Electric & $77 \%$ & $89 \%$ & $20 \%$ & $90 \%$ \\
Fraction Natural gas & $23 \%$ & $11 \%$ & $10 \%$ \\
\hline
\end{tabular}

Table A3. NWC Energy Use Intensity (EUI) Summary (normal load profile) for the various building complexes, including the phase and year for which their energy load and generation comes on-line in the 30-year energy and economic analysis. The healthcare and secondary school EUI are considerably higher than existing buildings, while the warehouse is much lower than the historical buildings, reflective of advances in building construction energy efficiency.

\begin{tabular}{|c|c|c|c|c|}
\hline Phase (Year) & Building/Complex & $\begin{array}{l}\text { IECC Representative } \\
\text { Building Type }\end{array}$ & $\begin{array}{c}\text { Size } \\
{\left[\mathrm{m}^{2}\left(\mathrm{ft}^{2}\right)\right]}\end{array}$ & $\begin{array}{c}\text { EUI } \\
{\left[\mathrm{MJ} / \mathrm{m}^{2}-\mathrm{yr} .\right.} \\
\left.\left(\mathbf{k B T U} / \mathrm{ft}^{2}-\mathrm{yr} .\right)\right]\end{array}$ \\
\hline 0 (existing) & Coliseum & $\mathrm{n} / \mathrm{a}-$ utility bills & $16,100(173,000)$ & $408(36)$ \\
\hline 0 (existing) & Stadium/Hall of Education & $\mathrm{n} / \mathrm{a}-$ utility bills & $24,000(258,000)$ & $508(45)$ \\
\hline 0 (existing) & Events Center & $\mathrm{n} / \mathrm{a}-$ utility bills & $23,300(251,000)$ & $286(25)$ \\
\hline $1(1)$ & Maintenance (renovation) & Warehouse & $5410(58,200)$ & $183(16)$ \\
\hline $1(1)$ & Stock Show Arena \& Auction & Warehouse & $3630(39,000)$ & $183(16)$ \\
\hline $2(2)$ & CSU WRC & Secondary School & $13,800(148,000)$ & $490(43)$ \\
\hline $3(3)$ & Animal Health & Outpatient Healthcare & $7240(77,900)$ & $1180(104)$ \\
\hline $4(6)$ & Livestock Hall \& Arena & Warehouse & $30,200(325,000)$ & $183(16)$ \\
\hline $5(9)$ & Equestrian Arenas \& Paddocks & Warehouse & $47,200(508,000)$ & $183(16)$ \\
\hline \multicolumn{4}{|c|}{ Weighted Average: } & $331(29)$ \\
\hline
\end{tabular}




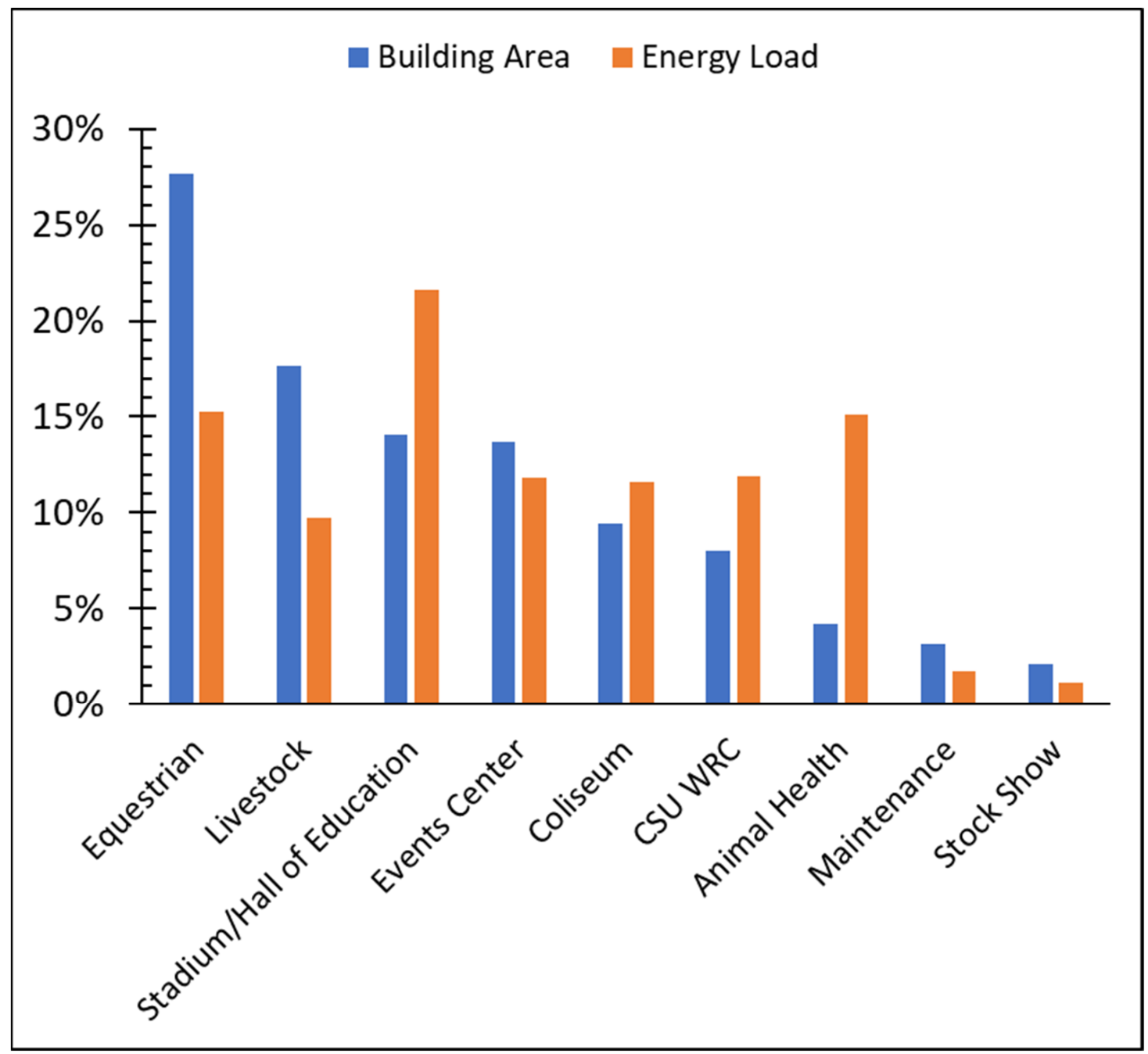

Figure A2. NWC campus distribution of building area and energy load. While representing only $12 \%$ of building area, the CSU WRC and Animal Health buildings comprise 27\% of the energy load. Conversely, the Livestock and Equestrian complexes represent $45 \%$ of building area, but only $25 \%$ of energy load. The existing Stadium/Hall of Education complex is the largest single building energy load.

Table A4. PV Production Estimation on a per roof segment basis for the various building complexes of the NWC. The high energy use intensity Water Resource Center (WRC) and Animal Health buildings are unable to generate sufficient PV energy to offset their own needs, while the large area and low energy use intensity Stock Show, Livestock, and Equestrian building generate a surplus of PV energy relative to their own individual energy use.

\begin{tabular}{|c|c|c|c|c|c|c|}
\hline Building/Use & $\begin{array}{c}\text { Size } \\
{[\mathrm{sq} \mathrm{ft.]}}\end{array}$ & $\begin{array}{l}\text { Roof } \\
\text { Type }\end{array}$ & $\begin{array}{c}\text { Number of } \\
\text { Roof } \\
\text { Segments }\end{array}$ & $\begin{array}{c}\text { Available PV } \\
\text { Area }\left[\mathrm{m}^{2}\right]\end{array}$ & $\begin{array}{c}\text { Annual PV } \\
\text { Capacity } \\
{[\mathrm{kWh}]}\end{array}$ & $\begin{array}{l}\text { Ratio of Building } \\
\text { Energy Needs }\end{array}$ \\
\hline Stock Show Arena \& Auction & 39,000 & pitched & 4 & 2740 & 571,000 & $310 \%$ \\
\hline Livestock Hall & 221,000 & pitched & 5 & 11,800 & $2,520,000$ & $241 \%$ \\
\hline Livestock Arena & 103,000 & pitched & 2 & 8250 & $1,730,000$ & $353 \%$ \\
\hline Equestrian Barn & 220,000 & pitched & 3 & 5440 & $1,170,000$ & $113 \%$ \\
\hline Equestrian Warm-up $(2 \times)$ & 39,600 & pitched & 2 & 1420 & 297,000 & $159 \%$ \\
\hline Equestrian Paddock $(2 \times)$ & 61,600 & pitched & 3 & 3070 & 650,000 & $223 \%$ \\
\hline $\begin{array}{l}\text { Equestrian Arena } \\
(\mathrm{Sm}+\mathrm{Lg})\end{array}$ & 187,000 & flat & 2 & 15,000 & $2,134,000$ & $242 \%$ \\
\hline CSU WRC (2-story) & 148,000 & flat & 2 & 5780 & 821,000 & $41 \%$ \\
\hline Animal Health & 77,900 & flat & 1 & 6230 & 885,000 & $34 \%$ \\
\hline
\end{tabular}


Table A5. Summary Heating, Ventilation, and Air-Conditioning (HVAC) Load table for Ground Source Heat Pump study of CSU's Moby Arena used to determine a cost premium metric $(\$ / \mathrm{kW})$ for installation of a heat pump system relative to a conventional heating and cooling system.

\begin{tabular}{cc}
\hline Building Load & Capacity \\
\hline Peak Cooling Load & $6483 \mathrm{MBh}(540$ tons $)$ \\
\hline Peak Heating Load & $8266 \mathrm{MBh}$ \\
\hline
\end{tabular}

Table A6. Summary Construction Cost Comparison table for Ground Source Heat Pump study of CSU's Moby Arena used to determine a cost premium metric $(\$ / \mathrm{kW})$ for installation of a heat pump system relative to a conventional heating and cooling system.

\begin{tabular}{|c|c|c|}
\hline Item & Cost & $\$ / \mathrm{ft}^{2}$ \\
\hline $\begin{array}{c}\text { Alternative } 1 \text { (Geothermal) } \\
\text { Estimated Cost }\end{array}$ & $\$ 8,400,000$ & $\$ 33.86$ \\
\hline $\begin{array}{c}\text { Alternative } 2 \text { (Conventional) } \\
\text { Estimated Cost }\end{array}$ & $\$ 7,224,000$ & $\$ 29.12$ \\
\hline
\end{tabular}

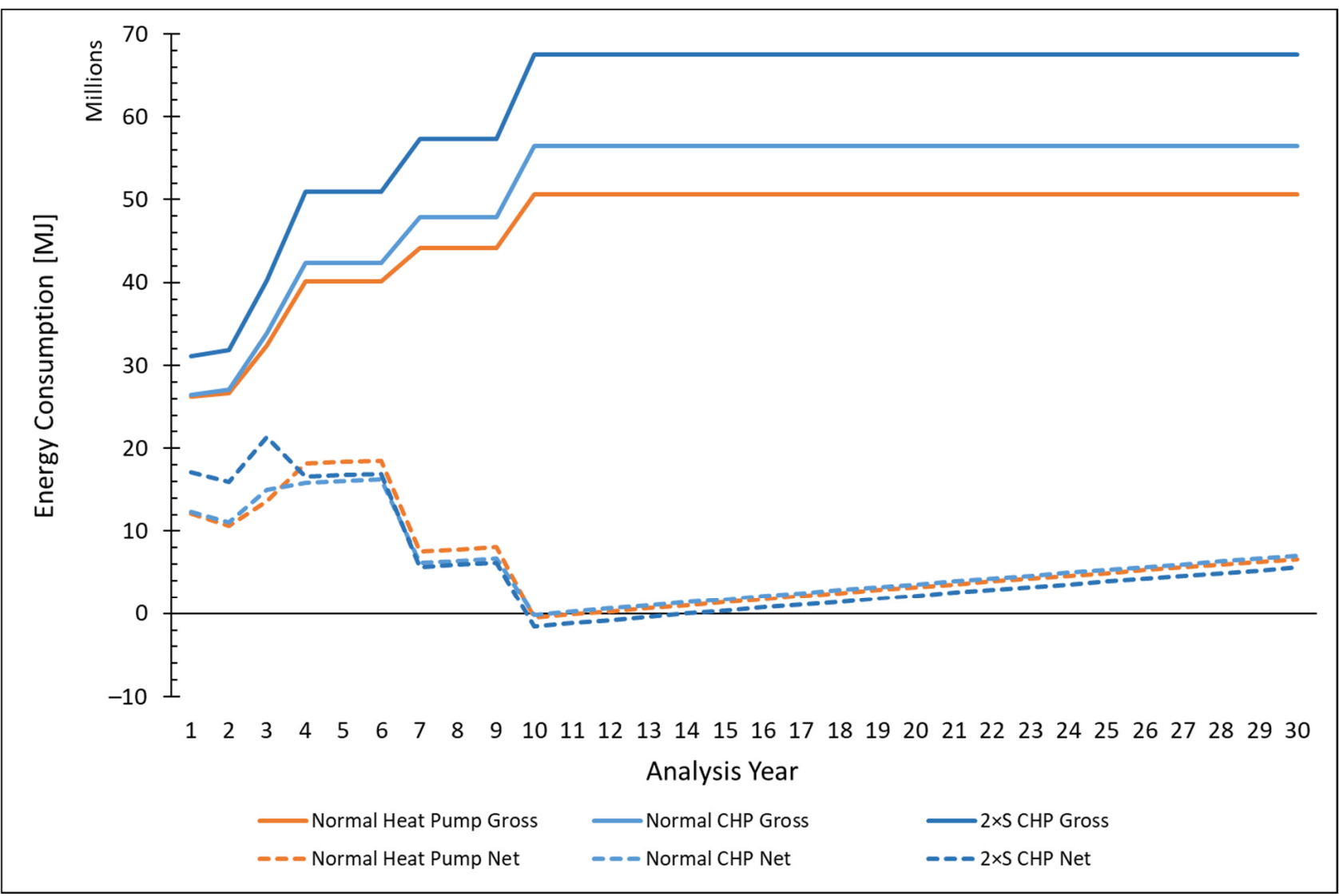

Figure A3. NWC annual gross and net energy load over 30-year economic analysis period. Five phases of building construction are considered, such that year 10 is the first year reflecting full build-out. Gradual increase in net load over time is reflective of assumed $0.75 \%$ degradation in annual PV generation. 


\section{References}

1. Polly, B.; Kutscher, C.; Macumber, D.; Schott, M. From zero energy buildings to zero energy districts. In Proceedings of the 2016 ACEEE Summer Study Energy Efficiency in Buildings, Pacific Grove, CA, USA, 21-26 August 2016.

2. Pless, S.; Torcellini, P. Net-Zero Energy Buildings: A Classification System Based on Renewable Energy Supply Options; NREL/TP-55044586; National Renewable Energy Lab. (NREL): Golden, CO, USA, 2010. [CrossRef]

3. Carlisle, N.; Van Geet, O.; Pless, S. Definition of a "Zero Net Energy" Community 2009; NREL/TP-7A2-46065; National Renewable Energy Lab. (NREL): Golden, CO, USA, 2009. [CrossRef]

4. Attia, S.; Hamdy, M.; O’Brien, W.; Carlucci, S. Assessing gaps and needs for integrating building performance optimization tools in net zero energy buildings design. Energy Build. 2013, 60, 110-124. [CrossRef]

5. Shi, Z.; Fonseca, J.A.; Schlueter, A. A review of simulation-based urban form generation and optimization for energy-driven urban design. Build. Environ. 2017, 121, 119-129. [CrossRef]

6. Wang, C.; Kilkis, S.; Tjernström, J.; Nyblom, J.; Martinac, I. Multi-objective optimization and parametric analysis of energy system designs for the Albano University Campus in Stockholm. Procedia Eng. 2017, 180, 621-630. [CrossRef]

7. Sameti, M.; Haghighat, F. Integration of distributed energy storage into net-zero energy district systems: Optimum design and operation. Energy 2018, 153, 575-591. [CrossRef]

8. Doubleday, K.; Parker, A.; Hafiz, F.; Irwin, B.; Hancock, S.; Pless, S.; Hodge, B.M. Toward a subhourly net zero energy district design through integrated building and distribution system modeling. J. Renew. Sustain. Energy 2019, 11, 36301. [CrossRef]

9. Amaral, A.R.; Rodrigues, E.; Rodrigues Gaspar, A.; Gomes, Á. Review on performance aspects of nearly zero-energy districts. Sustain. Cities Soc. 2018, 43, 406-420. [CrossRef]

10. Lopes, R.A.; Martins, J.; Aelenei, D.; Lima, C.P. A cooperative net zero energy community to improve load matching. Renew. Energy 2016, 93, 1-13. [CrossRef]

11. Parra, D.; Swierczynski, M.; Stroe, D.I.; Norman, S.A.; Abdon, A.; Worlitschek, J.; O’Doherty, T.; Rodrigues, L.; Gillott, M.; Zhang, X.; et al. An interdisciplinary review of energy storage for communities: Challenges and perspectives. Renew. Sustain. Energy Rev. 2017, 79, 730-749. [CrossRef]

12. Zakeri, B.; Syri, S. Electrical energy storage systems: A comparative life cycle cost analysis. Renew. Sustain. Energy Rev. 2015, 42, 569-596. [CrossRef]

13. Tervo, E.; Agbim, K.; DeAngelis, F.; Hernandez, J.; Kim, H.K.; Odukomaiya, A. An economic analysis of residential photovoltaic systems with lithium ion battery storage in the United States. Renew. Sustain. Energy Rev. 2018, 94, 1057-1066. [CrossRef]

14. Kalkan, N.; Bercin, K.; Cangul, O.; Morales, M.G.; Saleem, M.M.K.M.; Marji, I.; Metaxa, A.; Tsigkogianni, E. A renewable energy solution for Highfield Campus of University of Southampton. Renew. Sustain. Energy Rev. 2011, 15, 2940-2959. [CrossRef]

15. Kwan, C.L.; Hoffmann, A. The Los Angeles Community College District: Establishing a net-zero energy campus. In Sustainable Communities Design Handbook; Butterworth-Heinemann: Oxford, UK, 2010; pp. 181-215. [CrossRef]

16. Ferrari, S.; Beccali, M. Energy-environmental and cost assessment of a set of strategies for retrofitting a public building toward nearly zero-energy building target. Sustain. Cities Soc. 2017, 32, 226-234. [CrossRef]

17. Pless, S.; Polly, B. Communities of the Future: Accelerating Zero Energy District Master Planning; NREL/CP-5500-71841; National Renewable Energy Lab. (NREL): Golden, CO, USA, 2018.

18. Allegrini, J.; Orehounig, K.; Mavromatidis, G.; Ruesch, F.; Dorer, V.; Evins, R. A review of modelling approaches and tools for the simulation of district-scale energy systems. Renew. Sustain. Energy Rev. 2015, 52, 1391-1404. [CrossRef]

19. U.S. Department of Energy's, Building Technologies Office. Index Energyplus.Net 2018. Available online: https:/ / energyplus.net/ (accessed on 20 March 2020).

20. National Western Center Partners. 5348a90d386c0515d63b98f9b274d3b6aab8541b @ nationalwesterncenter.com 2015. Available online: https:/ / nationalwesterncenter.com/about/the-redevelopment-process/sustainability-regen/ (accessed on 21 July 2018).

21. National Western Center Partners. National Western Center Master Plan 2015. Available online: https:/ / denvernwc.wpengine. com/wp-content/uploads/2017/10/NWC-Master-Plan-2015.pdf (accessed on 6 December 2021).

22. Marique, A.-F.; Reiter, S. A simplified framework to assess the feasibility of zero-energy at the neighbourhood/community scale. Energy Build. 2014, 82, 114-122. [CrossRef]

23. NREL. Index @ Pvwatts.Nrel.Gov 2019. Available online: http:/ / pvwatts.nrel.gov/ (accessed on 8 May 2020).

24. U.S. DOE. Prototype_Models www.energycodes.gov 2015. Available online: https://www.energycodes.gov/development/ commercial/prototype_models (accessed on 21 July 2018).

25. Fu, R.; Feldman, D.; Margolis, R.; Woodhouse, M.; Ardani, K. U.S. Solar Photovoltaic System Cost Benchmark: Q1 2017; NREL/TP6A20-68925; National Renewable Energy Lab (NREL): Golden, CO, USA, 2017. [CrossRef]

26. Zsiborács, H.; Hegedúsné Baranyai, N.; Csányi, S.; Vincze, A.; Pintér, G. Economic analysis of grid-connected PV system regulations: A Hungarian case study. Electronics 2019, 8, 149. [CrossRef]

27. Deru, M.; Field, K.; Studer, D.; Benne, K.; Griffith, B.; Torcellini, P.; Liu, B.; Halverson, M.; Winiarski, D.; Rosenberg, M.; et al. U.S. Department of Energy Commercial Reference Building Models of the National Building Stock; TP-5500-46861; National Renewable Energy Lab. (NREL): Golden, CO, USA, 2011; pp. 1-118.

28. U.S. DOE. Building Science-Based Climate Maps 2013:2. Available online: https://www1.eere.energy.gov/buildings/ publications/pdfs/building_america/4_3a_ba_innov_buildingscienceclimatemaps_011713.pdf (accessed on 6 December 2021). 
29. Jenkins, T. Solar-Powered Water Pump Design Spreadsheet Version II: User Manual; New Mexico State University: Las Cruces, NM, USA, 2014; pp. 1-12. [CrossRef]

30. Riley, D.; Hansen, C. Sun-relative Pointing for dual-axis solar trackers employing azimuth and elevation rotations. J. Sol. Energy Eng. 2015, 137, 31006-31008. [CrossRef]

31. Solarworld. SW 285-300 MONO (5-busbar) n.d.:3-4. Available online: https://www.solaris-shop.com/content/SW300\%20Plus\% 20Mono\%20Specs.pdf (accessed on 6 July 2018).

32. NREL. Tech-Lcoe-Re-Cost-Est www.nrel.gov 2016. Available online: https://www.nrel.gov/analysis/tech-lcoe-re-cost-est.html (accessed on 30 September 2018).

33. City and County of Denver. Rfq-Nwc-Stockyards www.denvergov.org. 2018 n.d. Available online: https://www.denvergov.org/ content/denvergov / en/contract-administration/current-bidding-opportunities/2018/rfq-nwc-stockyards.html (accessed on 31 July 2018).

34. Bi, X.; Naimi, L.J.; Narayan, S.; Mani, S.; Womac, A.R.; Hoque, M.; Womac, A.R.; Narayan, S.; Ye, X.P. Bulk density of wet and dry wheat straw and switchgrass particles. Appl. Eng. Agric. 2013, 24, 351-358. [CrossRef]

35. Community Power Corporation. Biomax-Systems @ www.gocpc.com 2016. Available online: http://www.gocpc.com/biomaxsystems.html (accessed on 30 October 2018).

36. McFarland, W. (Chief Executive Officer of Biomax-Systems Inc.). Phone Conversation, 30 October 2018.

37. Kim, J.; Kim, J.; Kim, J.; Yoo, C.; Moon, I. A simultaneous optimization approach for the design of wastewater and heat exchange networks based on cost estimation. J. Clean Prod. 2009, 17, 162-171. [CrossRef]

38. Cole, W.; Frazier, A.W.; Cole, W.; Frazier, A.W. Cost Projections for Utility-Scale Battery Storage Cost Projections for Utility-Scale Battery Storage; NREL/TP-6A20-73222; National Renewable Energy Lab. (NREL): Golden, CO, USA, 2019.

39. Enphase IQ Battery 10T Datasheet, n.d. Available online: https://enphase.com/installers/storage/iq-battery-10t (accessed on 21 November 2021).

40. Schimpe, M.; Naumann, M.; Truong, N.; Hesse, H.C.; Santhanagopalan, S.; Saxon, A.; Jossen, A. Energy efficiency evaluation of a stationary lithium-ion battery container storage system via electro-thermal modeling and detailed component analysis. Appl. Energy 2018, 210, 211-229. [CrossRef]

41. Dobos, A.P. PVWatts Version 5 Manual; NREL/TP-6A20-62641; National Renewable Energy Lab. (NREL): Golden, CO, USA, 2014; p. 3. [CrossRef]

42. Sartori, I.; Napolitano, A.; Voss, K. Net zero energy buildings: A consistent definition framework. Energy Build. 2012, 48, $220-232$. [CrossRef]

43. NREL. Equations and Variables in ATB. Annual Technology Baseline 2020. Available online: https://atb.nrel.gov/electricity/20 20/equations-variables.php (accessed on 2 December 2020).

44. Short, W.; Packey, D.; Holt, T. A manual for the economic evaluation of energy efficiency and renewable energy technologies. Renew. Energy 1995, 95, 73-81. [CrossRef]

45. NREL. Electricity ATB Data Download. Annual Technology Baseline 2020. Available online: https://atb.nrel.gov/electricity/20 20/data.php (accessed on 2 December 2020).

46. NREL. Archives: NREL ATB and Standard Scenarios. Annual Technology Baseline 2020. Available online: https://atb.nrel.gov/ electricity/archives.html (accessed on 2 December 2020).

47. Peterson, K.; Torcellini, P.; Grant, R. A Common Definition for Zero Energy Buildings; DOE/EE-1247; US Department of Energy: Washington, DC, USA, 2015; p. 22.

48. U.S. DOE. Commercial Building Benchmarks Energy Use Intensities. 2009. Available online: https://www.energy.gov/sites/ prod/files/2013/12/f5/all_euis.pdf (accessed on 6 December 2021).

49. U.S. DOE. Commercial Iecc-Building-Models-Warehouse-Non-Refrigerated @ www.energycodes.gov 2015. Available online: https:/ / www.energycodes.gov/commercialiecc-building-models-warehouse-non-refrigerated (accessed on 21 July 2018).

50. Patsios, C.; Wu, B.; Chatzinikolaou, E.; Rogers, D.J.; Wade, N.; Brandon, N.P.; Taylor, P. An integrated approach for the analysis and control of grid connected energy storage systems. J. Energy Storage 2016, 5, 48-61. [CrossRef]

51. Annual Energy Outlook 2019 with Projections to 2050; U.S. Energy Information Administration: Washington, DC, USA, 2019. Available online: https:/ /www.eia.gov/outlooks/archive/aeo19/ (accessed on 6 December 2021).

52. U.S. Energy Information Administration. Wholesale Electricity and Natural Gas Market Data @ www.eia.gov n.d. Available online: https:/ / www.eia.gov/electricity/wholesale/ (accessed on 20 April 2020). 